ARTICLE

DOI: $10.1038 / \mathrm{s} 41467-018-03652-8$

\title{
The ng_ל1 toxin of the gonococcal epsilon/zeta toxin/antitoxin system drains precursors for cell wall synthesis
}

\author{
Andrea Rocker ${ }^{1}$, Madeleine Peschke ${ }^{1}$, Tiia Kittilä ${ }^{1}$, Roman Sakson$^{1}$, Clara Brieke $^{1} \&$ Anton Meinhart ${ }^{1,2}$
}

\begin{abstract}
Bacterial toxin-antitoxin complexes are emerging as key players modulating bacterial physiology as activation of toxins induces stasis or programmed cell death by interference with vital cellular processes. Zeta toxins, which are prevalent in many bacterial genomes, were shown to interfere with cell wall formation by perturbing peptidoglycan synthesis in Grampositive bacteria. Here, we characterize the epsilon/zeta toxin-antitoxin (TA) homologue from the Gram-negative pathogen Neisseria gonorrhoeae termed ng_ع1 / ng_ $\zeta 1$. Contrary to previously studied streptococcal epsilon/zeta TA systems, ng_ $\varepsilon 1$ has an epsilon-unrelated fold and ng_ $\zeta 1$ displays broader substrate specificity and phosphorylates multiple UDPactivated sugars that are precursors of peptidoglycan and lipopolysaccharide synthesis. Moreover, the phosphorylation site is different from the streptococcal zeta toxins, resulting in a different interference with cell wall synthesis. This difference most likely reflects adaptation to the individual cell wall composition of Gram-negative and Gram-positive organisms but also the distinct involvement of cell wall components in virulence.
\end{abstract}

\footnotetext{
${ }^{1}$ Department of Biomolecular Mechanisms, Max Planck Institute for Medical Research, Jahnstr. 29, 69120 Heidelberg, Germany. ${ }^{2}$ Present address: Research Institute for Molecular Pathology (IMP), Vienna Biocenter (VBC), Campus-Vienna-Biocenter 1, 1030 Vienna, Austria. These authors contributed equally: Andrea Rocker, Madeleine Peschke. Correspondence and requests for materials should be addressed to A.M. (email: Anton.Meinhart@imp.ac.at)
} 
D acterial toxin-antitoxin (TA) modules are poisonous gene pairs coding for a toxin and its cognate antitoxin. TA systems are highly prevalent in bacterial genomes ${ }^{1,2}$ and in most cases the neutralizing antitoxin is encoded together with the toxin on a bicistronic locus ${ }^{3,4}$. TA modules were initially discovered as plasmid stabilizing systems, but have since been shown to regulate persister cell and biofilm formation, to act as stress response elements and even to increase virulence of pathogenic bacteria $^{5-7}$. Because of their roles in bacterial survival, TA systems have become interesting targets for the development of new antimicrobial agents. Detailed understanding of TA systems is, however, required before such approaches can be efficiently utilized.

TA modules can be grouped into six different types varying in their mode of toxin inhibition ${ }^{8}$. Typically, the toxin is a protein whereas the antitoxin can be either a protein or a non-coding RNA. The best characterized family of TA systems are the type II systems where both the toxin and the antitoxin are proteins ${ }^{3,9}$. Neutralization of the toxin is achieved in type II systems through complex formation between the two proteins. Regardless of the TA system type, toxins interfere with vital cellular pathways leading to cell death or dormancy ${ }^{10}$. Most toxins known to date target protein translation, e.g., by cleavage of mRNAs ${ }^{11-13}$, modification of tRNAs, ${ }^{14,15}$ or inhibition of ribosome activity ${ }^{16}$. However, toxins have also been shown to inhibit replication ${ }^{17,18}$ and to prevent ATP synthesis by pore formation ${ }^{19,20}$. In addition, one group of type II toxins, the so called zeta toxins, interfere with cell wall integrity by phosphorylating cytosolic cell wall precursors $^{21}$ and are highly prevalent in pathogenic bacteria ${ }^{22}$.

Zeta toxins are canonical type II TA systems in which the toxicity of zeta is inhibited by the epsilon antitoxin. The first characterized members of this family were the plasmid encoded $\varepsilon / \zeta$ from Streptococcus pyogenes ${ }^{23}$ and the chromosomally encoded PezAT systems from Streptococcus pneumoniae ${ }^{24}$. Zeta toxins adopt a classical phosphotransferase fold ${ }^{24,25}$ with a central Ploop motif important for ATP binding ${ }^{26}$. In contrast, the cognate epsilon antitoxin folds into a simple three helix bundle domain. Both streptococcal systems form an epsilon ${ }_{2}$ zeta $_{2}$ heterotetramer, in which the ATP binding to the active site of zeta is blocked by epsilon impairing zeta activity. In fact, zeta toxins use ATP to phosphorylate UDP- $N$-acetylglucosamine (UNAG) to form UDP- $N$-acetylglucosamine-3'phosphate (UNAG-3P) ${ }^{21}$ and thereby modify this essential peptidoglycan precursor. Biosynthesis of peptidoglycan is highly conserved in bacteria and requires a cascade of enzymes that sequentially modify $\mathrm{UNAG}^{27}$. Initially, an enolpyruvate group is added to the $\mathrm{C}^{\prime}-\mathrm{OH}$ group of UNAG by MurA yielding UDP-acetylglucosamine enolpyruvate (EPUNAG). Because zeta toxins and MurA act on the same $\mathrm{C}^{\prime}{ }^{\prime}-\mathrm{OH}$ group, formation of UNAG-3P inhibits formation of EP-UNAG. When zeta is inactive, e.g., by binding to the epsilon antitoxin, the
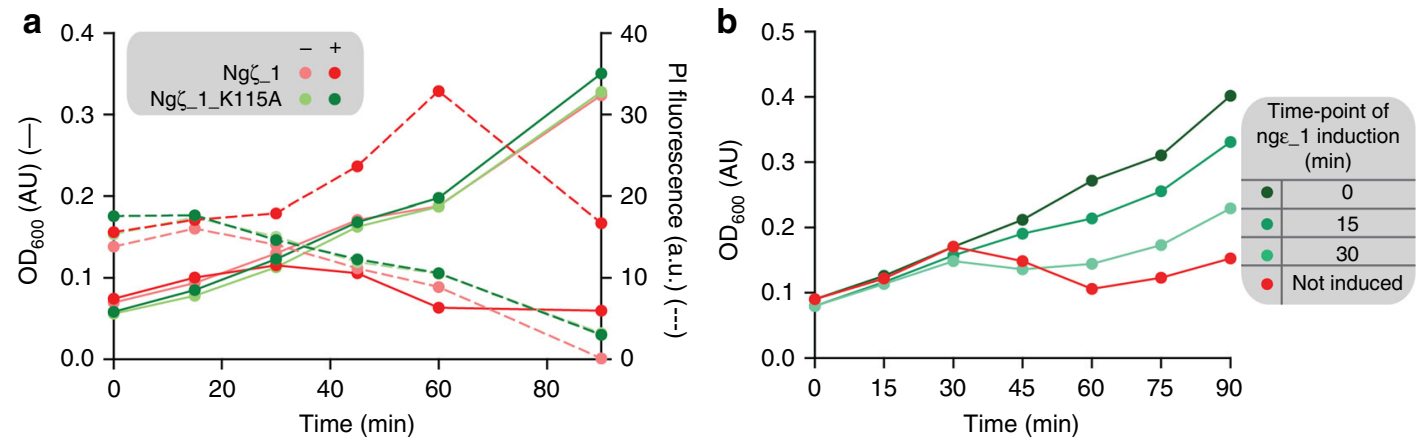

C
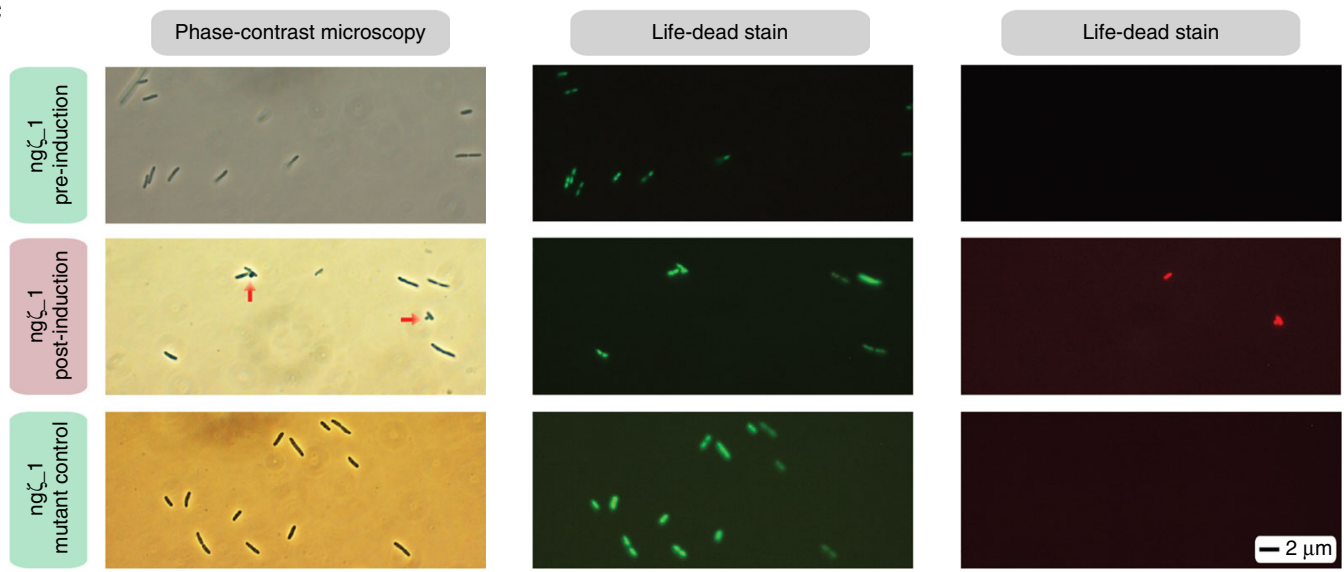

Fig. $1 \mathrm{Ng} \zeta_{-} 1$ expression in E. coli cells causes a lytic phenotype compensated by nge_1 co-expression. a Growth curves of E. coli C41(DE3) cells expressing ng $\zeta_{-} 1$ (red solid line and left $Y$-axis) or ng $\zeta_{-} 1(\mathrm{~K} 115 \mathrm{~A}$ ) (forest-green solid line and left $Y$-axis) together with the corresponding propidium iodide influx into the cells (dashed lines similarly colored and right $Y$-axis). Control experiments in which expression of ng $\zeta_{-} 1$ or ng $\zeta_{-} 1$ (K115A) was not induced are shown in light pink and lime-green. Note that growth curves of the two uninduced cell cultures as well as the PI measurements of the mutated variant (induced and

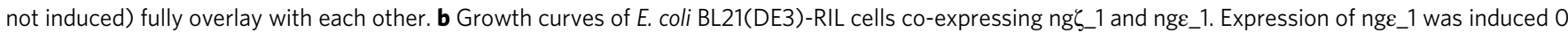
(forest-green), 15 (lime-green) and 30 min (pale-green) subsequent to $n g \zeta_{-} 1$ induction. The control experiment in which expression of nge_1 was not induced is shown in red. c Phase contrast and fluorescence microscopy (live-dead stain) of E. coli C41(DE3) cells before and after ng $\zeta_{-} 1$ induction (30 min) and the control experiment using the inactive $n g \zeta_{-} 1(\mathrm{~K} 115 \mathrm{~A})$ mutant. Cells with green fluorescence have intact cell membranes and are alive. Membrane permeable cells have red fluorescence due to propidium iodide influx. Resolved bulges due to cell wall extrusions in phase-contrast microscopy images are highlighted with red arrows 
enolpyruvate moiety of EP-UNAG is reduced by MurB yielding UDP-muramic acid (UNAM), the activated sugar to which a peptide stem is attached. Importantly, UNAG-3P is not only a dead-end product of zeta toxins but acts as a potent inhibitor of MurA $^{21}$. Eventually, the combined types of MurA inhibition stall de novo peptidoglycan synthesis at this early step and thus cause cell lysis in rapidly dividing bacteria.

Only epsilon/zeta modules of Gram-positive bacteria have been characterized so far in detail, but homologs are also highly prevalent in Gram-negative bacteria ${ }^{22}$. In contrast to zeta toxins from Gram-positive prokaryotes, the few investigated homologous TA systems of Gram-negative bacteria seem to be much more diverse in their function and mechanisms. For instance, the structurally homologous plant effector protein AvrRxo1 from Xanthomonas $^{28}$ functions as a bacterial TA-system as well ${ }^{29}$. AvrRxol has been shown to phosphorylate NAD and its precursors NAAD in vitro and causes massive $3^{\prime}$-NADP accumulation in vivo ${ }^{30,31}$. On the other side, a zeta homologue that is prevalent in Escherichia coli strains combines toxin and antitoxin functionalities in a single polypeptide chain ${ }^{32}$.

A prototype of a Gram-negative epsilon/zeta TA module, the epsilon_1/zeta_1 (nge_1/ng $\zeta_{-}$) TA system, is encoded by Neisseria gonorrhoeae, an obligate human pathogen causing the sexually transmitted disease gonorrhoea ${ }^{33}$. Traditional antibiotic treatment of gonorrhoea consists of ampicillin and tetracycline but this therapy is threatened by the spread of antibiotic resistances. High-level tetracycline resistance is conferred by the tet $M$ determinant of $25.2 \mathrm{MDa}$ conjugative plasmids and can thereby rapidly spread across the population ${ }^{34}$. The tetM determinant was acquired by insertion into the genetic load region of smaller 24.5 MDa conjugative plasmids of the "Dutch" or "American" type ${ }^{33}$. Sequence analysis of the tetM-less ancestor as well as different $25.2 \mathrm{MDa}$ plasmids revealed the presence of the $n g \varepsilon_{-} 1 / n g \zeta_{-} 1$ locus in all plasmids ${ }^{33}$. Interestingly, all three different conjugative plasmids where shown to contain a second epsilon/zeta homologous locus that has diverged by extensive mutations between the $25.2 \mathrm{MDa}$ tet $M$-containing and the $24.5 \mathrm{MDa}$ conjugative plasmids. TetM-containing plasmids carry the epsilon_2/ zeta_2 locus, $24.5 \mathrm{MDa}$ conjugative plasmids carry the epsilon_3/ zeta_3 locus ${ }^{33}$. Whereas the diverged epsilon_2/zeta_2 and epsilon_3/zeta_3 TA systems seem to be very similar in their amino acid sequence to the well characterized streptococcal systems (around 40\% amino acid sequence homology), nge_1/ ng $\zeta 1$ seems to be very different even at this level. However, nothing is known about these two gene pairs and therefore the mechanistic relevance of two homologous systems on the same plasmid remained unclear so far. Thus, we set out to investigate the $n g \varepsilon_{-} 1 / n g \zeta_{-} 1$ locus of $N$. gonorrhoeae. We could show that ng $\zeta \_1$, like streptococcal zeta toxins, phosphorylates peptidoglycan precursors and efficiently inhibits cell wall synthesis. However, in contrast to the known zeta toxins, ng $\zeta_{-} 1$ showed topological rewiring and a hitherto unknown enzymatic activity by phosphorylating UDP-activated sugars at the $\mathrm{C}^{\prime}-\mathrm{OH}$ group of the hexose moiety. This phosphorylation led to formation of dead-end metabolites resulting in cell death by draining precursors required for cell wall synthesis. As phosphorylation of the $\mathrm{C}^{\prime}$-OH group has not been observed for the previously characterized epsilon/zeta systems, ng $\zeta \_1$ and its proteobacterial homologs form a yet undescribed subfamily of zeta toxins.

\section{Results}

ng $\_1$ forms a new subclass of zeta-like toxins. Bioinformatic analysis of $n g \varepsilon_{-} 1 / n g \zeta_{\_} 1$ revealed $n g \zeta_{\_} 1$ toxins to be prevalent in numerous $N$. gonorrhoeae isolates (with currently 46 different NCBI entries with $100 \%$ sequence identity) but also a significant number of closely related zeta homologs in more than 25 different, mainly pathogenic proteobacteria was found (Supplementary Fig. 1 and Supplementary Table 1). However, apart from being encoded on a bicistronic operon ${ }^{33}$ and harbouring a P-loop motive, a hallmark for ATP/GTP binding proteins ${ }^{26}$, ng $\zeta_{-} 1$ is remarkably different from the hitherto functionally characterized streptococcal zeta toxins ${ }^{21,35}$ in its primary sequence. Especially striking is that the P-loop motive is located much closer to the Cterminus when compared with streptococcal zeta toxins (Supplementary Fig. 1). Furthermore, also the nge_1 antitoxin has no similarities to any known epsilon protein. Thus, we first questioned, whether nge_1/ng $\zeta_{-} 1$ is a functional TA system at all.

When ng $\zeta_{-} 1$ was expressed in $E$. coli cells, we observed a strong lytic phenotype $30 \mathrm{~min}$ post-induction as monitored by a decrease in optical density at $600 \mathrm{~nm}\left(\mathrm{OD}_{600}\right)$ paired with an influx of propidium iodide (Fig. 1a). This toxic phenotype was suppressed
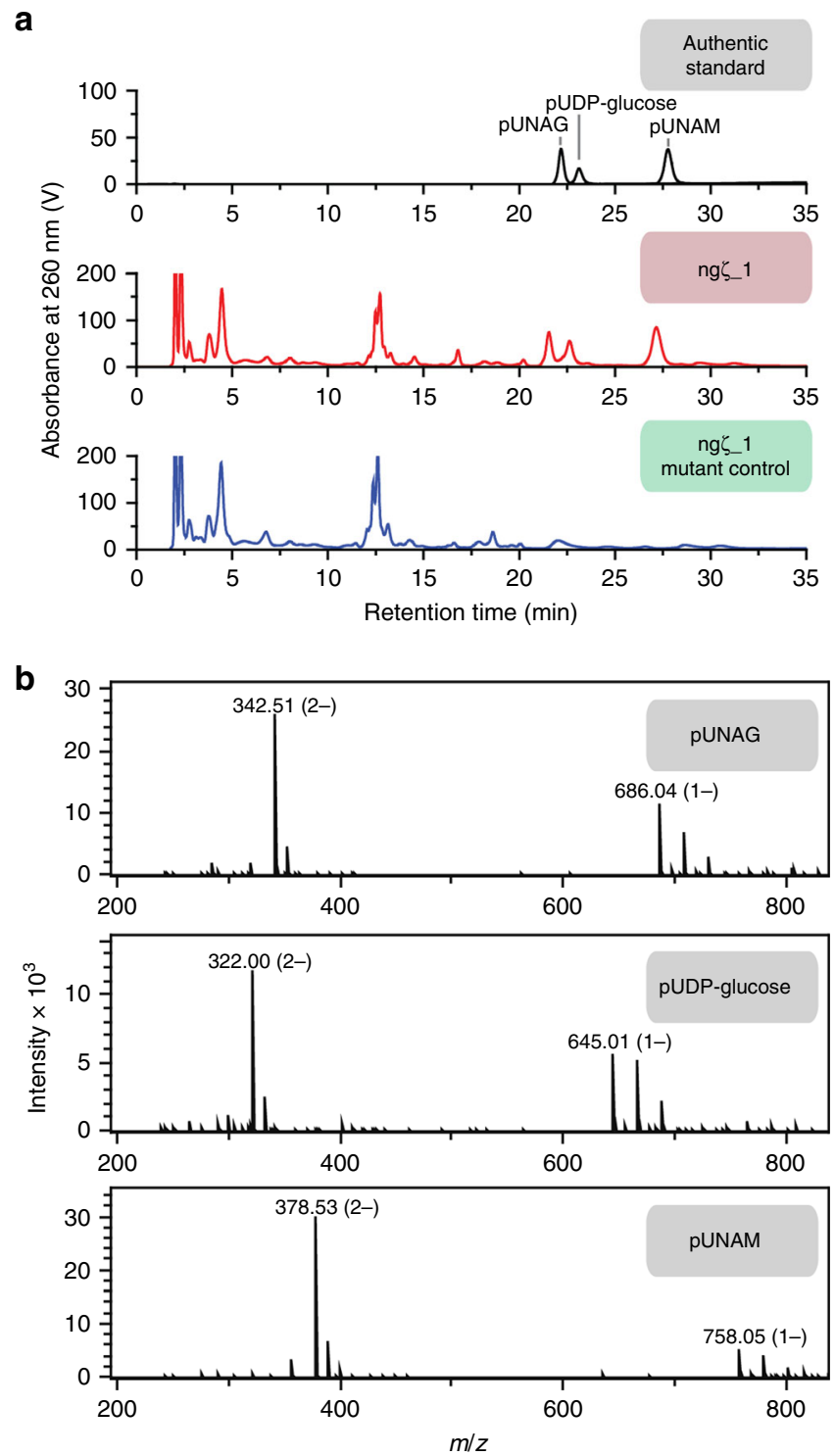

Fig. $2 \mathrm{Ng} \zeta_{-} 1$ phosphorylates different UDP-activated sugar species. a High pressure liquid chromatography analysis of small metabolite extracts from E. coli strain C41(DE3) cells expressing either ng __1 (red) or the inactive ng $\zeta_{-} 1($ K115A) variant (blue). Separation of UNAG, UDP-glucose and UNAM phosphorylated by ng $\zeta_{-} 1$ in vitro are shown for genuine standards (gray). b Mass determination of isolated, phosphorylated UNAG, UDP-glucose and UNAM by ESI-MS 
when nge_1 was simultaneously expressed in trans (Fig. 1b) indicating that nge_1 and $n g \zeta \_1$ together are indeed a TA pair. However, induction of nge_1 15 or $30 \mathrm{~min}$ after $\operatorname{ng} \zeta_{-} 1$ was not sufficient to inhibit the lytic phenotype completely (Fig. 1b). Similar as reported for the pneumococcal zeta toxin ${ }^{24}$, cell growth resumed in those experiments approximately $60 \mathrm{~min}$ after induction in all cases (Fig. 1b). Live/dead staining showed propidium iodide influx after induction of $n g \zeta_{-} 1$ and substantial cell wall defects of ng $\zeta_{1} 1$ expressing cells were observed (Fig. 1c). In order to provide evidence that a potential kinase activity of ng $\zeta \_1$ causes the lytic phenotype, the catalytic lysine residue in the P-loop was altered to alanine (ng $\zeta \_1(\mathrm{~K} 115 \mathrm{~A})$ ). Cells expressing this variant grew similar to cells co-expressing ng $\zeta_{-} 1$ and nge_1 (Fig. 1a, c). In conclusion, these findings strongly suggest that nge_1/ng $\zeta_{-} 1$ is indeed an authentic TA operon and that the toxic effect of ng $\zeta \_1$ is caused by its kinase activity.

ng $\zeta$ 1 phosphorylates peptidoglycan precursors. We wondered whether similar to the streptococcal zeta toxins ${ }^{21} \operatorname{ng} \zeta \_1$ also phosphorylates UNAG. Thus, we isolated small metabolite extracts from cells expressing $n g \zeta_{-} 1$ or the catalytically inactive variant and separated these extracts by high performance liquid chromatography (HPLC) (Fig. 2a). Surprisingly, we observed significant accumulation of three new species exclusively in ng $\zeta_{-} 1$-poisoned cell extracts, a finding which sets ng $\zeta_{-} 1$ apart from the hitherto characterized zeta toxins that only showed UNAG-3P enrichment ${ }^{21}$. These three species were isolated and their masses were determined by ESI-MS (Fig. 2b). The eluting species had a molecular mass comparable to that of a phosphorylated, deprotonated modification of UNAG $\left(m_{\mathrm{obs}}=686.04\right.$ $\mathrm{Da} ; m_{\text {calc. }}=686.04 \mathrm{Da}$; first eluting species), of UDP-glucose/ UDP-galactose $\left(m_{\text {obs. }}=645.01 \mathrm{Da} ; m_{\text {calc. }}=645.12 \mathrm{Da} ;\right.$ second eluting species), and of UNAM ( $m_{\text {obs. }}=758.05 \mathrm{Da} ; m_{\text {calc. }}=$ 758.39 Da, third eluting species). The second species is most likely phosphorylated UDP-glucose and not UDP-galactose since the E. coli strain C41(DE3) used in the experiment lacks the galT and galE genes ${ }^{36,37}$ and is thus defective in UDPgalactose synthesis ${ }^{38}$. Detecting phosphorylated UNAM was quite surprising as the hitherto characterized zeta toxins phosphorylate UNAG at $\mathrm{C}^{\prime}-\mathrm{OH}$ group ${ }^{21}$, which is blocked by a lactoyl group in case of UNAM (Supplementary Fig. 2). These results strongly suggest that ng $\zeta_{\_} 1$ phosphorylates UDP-sugars at a different site when compared with previously characterized zeta toxins.

To further verify the identity of these products, we tested the in vitro activity of $n g \zeta \_1$, which was separated from nge_1 chromatographically (Supplementary Fig. 3), for different UDPsugars. In a coupled spectroscopic assay, UNAM strongly stimulated ATPase activity of the protein, but we could not detect significant amounts of ADP production when either UNAG or UDP-glucose were added (Supplementary Fig. 4a).

To account for low reaction rates, we incubated ng $\zeta \_1$ with UDP-glucose (Supplementary Fig. 4b) or UNAG (Supplementary Fig. 4c) for up to $24 \mathrm{~h}$ and analysed the products by anion exchange chromatography. Indeed, phosphorylated products were detected in all cases. However, ADP production was found to be in excess over formation of phosphorylated UNAG when monitoring ng $\zeta_{1} 1$ activity over long periods of time. Surprisingly, the phosphorylated species vanished, when the assay was incubated for $12 \mathrm{~h}$ (Supplementary Fig. 4c) indicating a phosphatase activity of either ng $\zeta \_1$ or an unidentified contamination. Ultimately, the three phosphorylated in vitro products were isolated and analysed by HPLC, where they had the same retention times as the species formed in vivo (Fig. 2a). Altogether, these results show, that $\operatorname{ng} \zeta_{-} 1$ phosphorylates several

\section{Table 1 Data collection and refinement statistics}

\begin{tabular}{|c|c|c|c|}
\hline & $\begin{array}{l}\text { nge_1/ng } \zeta \_1 \\
\text { (K115A) Se- } \\
\text { Met }\end{array}$ & $\begin{array}{l}\text { nge_1/ng } \zeta_{-} 1 \\
\text { UNAM }\end{array}$ & $\begin{array}{l}\text { nge_1/ng } \zeta_{-} 1 \\
\text { UNAM-4P }\end{array}$ \\
\hline \multicolumn{4}{|l|}{ Data collection } \\
\hline $\begin{array}{l}\text { Space group } \\
\text { Cell dimensions }\end{array}$ & $P 2_{1}$ & $P 2_{1}$ & $P 2_{1}$ \\
\hline$a, b, c(\AA)$ & $\begin{array}{l}\text { 79.8, 149.6, } \\
125.1\end{array}$ & $\begin{array}{l}80.3,148.2 \\
124.4\end{array}$ & $\begin{array}{l}80.5,149.3 \\
125.4\end{array}$ \\
\hline$\alpha, \beta, \gamma\left({ }^{\circ}\right)$ & $90,94.82,90$ & $90,93.88,90$ & $90,94.35,90$ \\
\hline Resolution $(\AA)$ & $\begin{array}{l}50-2.4 \\
(2.8-2.4)\end{array}$ & $\begin{array}{l}50-2.7 \\
(2.8-2.7)\end{array}$ & $\begin{array}{l}50-2.8 \\
(2.9-2.8)\end{array}$ \\
\hline$R_{\text {meas. }}$ & $21.5(152.2)$ & 9.7 (99.1) & $11.3(92.0)$ \\
\hline$|/ \sigma|$ & $11.8(2.5)$ & $12.0(1.7)$ & $11.3(1.9)$ \\
\hline \multicolumn{4}{|l|}{ (\%) } \\
\hline Redundancy & 13.9 (13.7) & $4.2(4.1)$ & $4.1(3.8)$ \\
\hline $\begin{array}{c}\mathrm{CC}_{1 / 2} \\
\text { Refinement }\end{array}$ & \multicolumn{2}{|c|}{ Refinement } & $99.7(74.4)$ \\
\hline Resolution $(\AA)$ & $50-2.4$ & $50-2.7$ & $50-2.8$ \\
\hline No. reflections & 108,038 & 75,069 & 68,024 \\
\hline $\begin{array}{l}R_{\text {work }} / R_{\text {free }} \\
\text { No. atoms }\end{array}$ & $22.9 / 26.9$ & $22.1 / 24.6$ & $21.9 / 24.4$ \\
\hline Protein & 14,071 & 14,039 & 14,055 \\
\hline Ligand/ion & 110 & 262 & 275 \\
\hline Water & 110 & 104 & 141 \\
\hline \multicolumn{4}{|l|}{$B$-factor } \\
\hline Protein & 51.6 & 68.0 & 62.5 \\
\hline Ligand/ion & 65.3 & 68.4 & 55.4 \\
\hline Water & 40.8 & 48.8 & 42.8 \\
\hline \multicolumn{4}{|l|}{ R.m.s. deviations } \\
\hline$(\AA)$ Bond lengths & 0.011 & 0.008 & 0.007 \\
\hline Bond angles $\left({ }^{\circ}\right)$ & 1.38 & 1.17 & 1.13 \\
\hline $\begin{array}{r}\text { Atomic } \\
\text { coordinates }\end{array}$ & $6 \mathrm{EPG}$ & $6 \mathrm{EPH}$ & $6 \mathrm{EPI}$ \\
\hline
\end{tabular}

peptidoglycan precursors and most likely does so at a site different from the streptococcal zeta toxins.

Architecture of the $\mathbf{n g} \varepsilon \_1 / n g \zeta \_1$ TA-complex. In order to gain detailed insights into the zeta toxin encoded by Neisseria gonorrhoeae, we aimed at a structural characterization of substrate and product bound states of ng $\zeta_{-} 1$. To this end, we first determined the crystal structure of the catalytically inactive nge_1/ng $\zeta_{-} 1$ (K115A) selenomethionine substituted protein complex at $2.4 \AA$ resolution using single anomalous dispersion experiments (Table 1). We found four heterodimeric nge_1/ng $\zeta \_1(\mathrm{~K} 115 \mathrm{~A}) \mathrm{TA}$ complex molecules located in the asymmetric unit, a complex arrangement which we also observed in solution (Supplementary Fig. 5). Thus, the quaternary structure of the observed heterodimeric nge_1/ng $\zeta \_1$ protein complex is substantially different to the hitherto described heterotetrameric oligomeric state for all other epsilon/zeta TA complexes ${ }^{24,25}$.

In fact, not only the quaternary structure is set apart from known zeta toxins, but also the tertiary structure and mode of inhibition is very different to other zeta toxins. Strikingly nge_1 binds as an extended polypeptide stretch onto the molecular surface of ng $\zeta_{-} 1$ and does not fold into a globular domain (Fig. 3a, b). In contrast, the streptococcal epsilon antitoxins fold into three-helix bundles (Supplementary Fig. 6) and two epsilon molecules form the core of the heterotetrameric epsilon ${ }_{2} /$ zeta $_{2}$ protein complex ${ }^{24,25}$. Furthermore, the C-terminal part of the first helix, the second helix and the connecting loop region of 
a

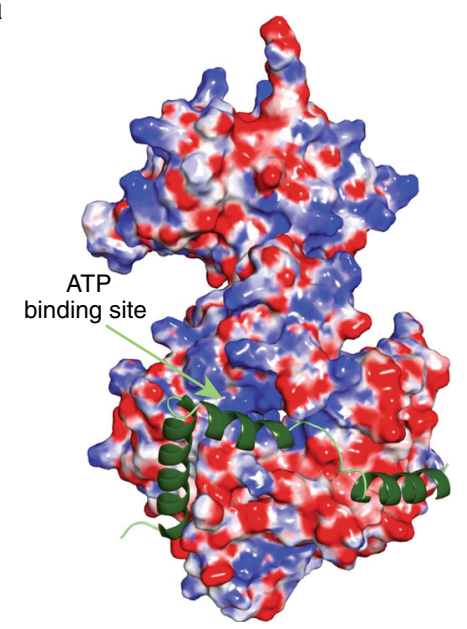

b

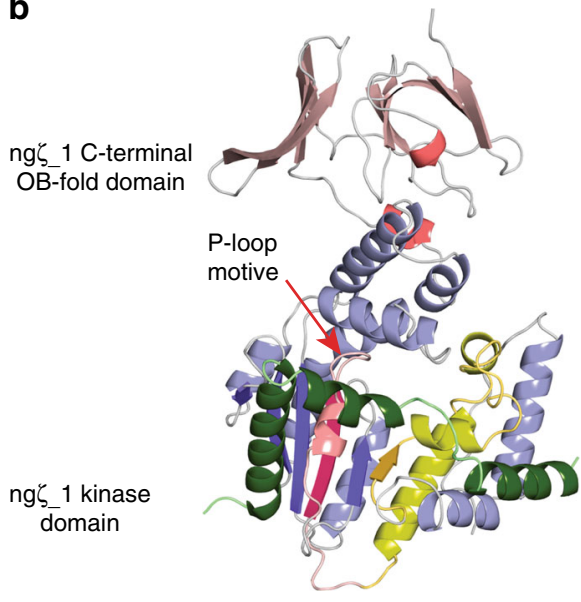

C

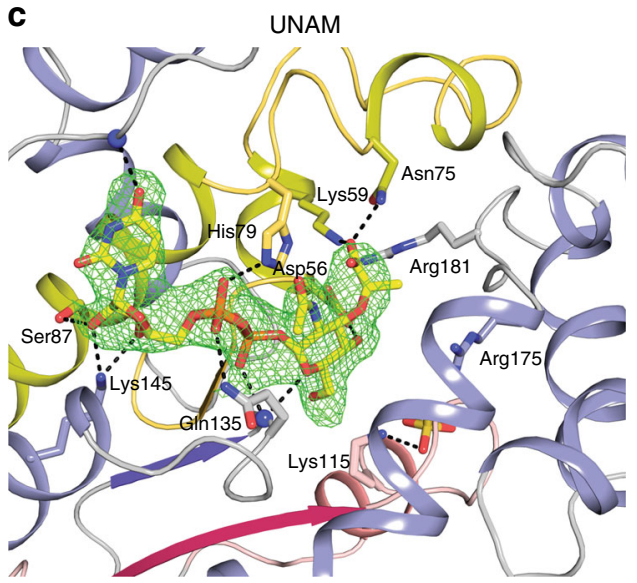

d

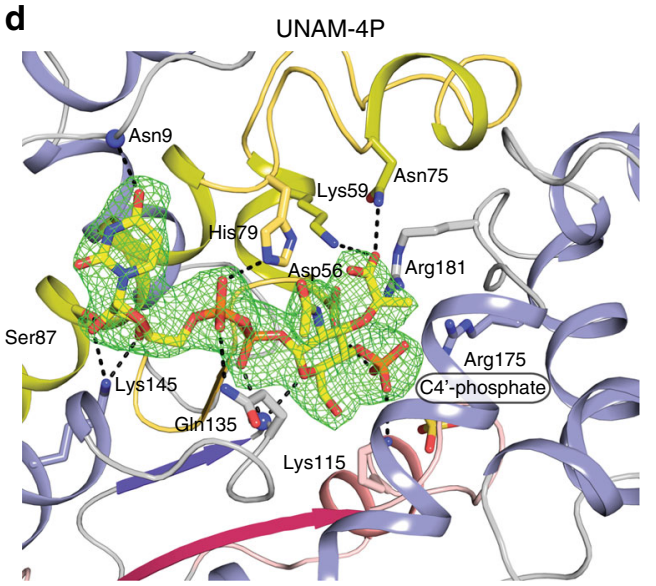

Fig. 3 Structure of the $n g \varepsilon_{-} 1 / n g \zeta_{-} 1$ TA complex and substrate binding mode. a Surface representation of ng $\zeta_{-} 1$ colored according to the electrostatic surface-potential and ng $\varepsilon_{-} 1$ depicted as ribbon model (forest-green). $\mathbf{b}$ Ribbon representation of $n g \zeta_{-} 1$ at the same orientation as in $\mathbf{a}$. Structural elements involved in topological rewiring are highlighted in red (strand)/pink (helix) and dark-yellow (strand)/yellow (helix). The C-terminal OB-fold domain is colored in red. Coloring is performed similar as in Supplementary Fig. 1. c, d Close-up view of the active site of ng $\zeta_{-} 1$ with the bound UNAM (c) and UNAM4P (d) molecules shown as stick model. Fo-Fc electron density map contoured at $3 \sigma$ with the ligand omitted before refinement is shown as a mesh

nge_1 cover the potential ATP binding site (Fig. 3a). In all other epsilon toxins, residues located in the N-terminal region of the first helix of the three-helix bundle protrude into the active site and block ATP binding to the toxic kinase domain ${ }^{24,25}$

In addition, also the tertiary structure of $\operatorname{ng} \zeta_{\_} 1$ is different to known zeta toxins, as it consists of two domains (Fig. 3b). The Nterminal domain has the classical fold of a nucleotide kinase to which a DALI search ${ }^{39}$ identified zeta toxins ${ }^{24,25}$ and AvrRxol from Xanthomonas ${ }^{28}$ to be the closest structural homologues. Although our initial analysis of the primary sequence did not identify these homologues, a structural alignment revealed that two sequence blocks were shuffled by swapping position within the polypeptide chain. Yet, two loop regions were topologically rewired in ng $\zeta \_1$ when compared with other zeta toxins leading to a similar tertiary structure albeit these two blocks occur at different position within the amino acid sequence (Supplementary Fig. 1). Nevertheless, residues that have previously been shown to be important for enzyme catalysis are found to be structurally conserved in ng $\zeta_{1}$. Finally, the C-terminal domain has the fold of an oligonucleotide/oligosaccharide binding domain (OB-domain) and consists of a five-stranded Greek-key $\beta$-barrel that is in an open distorted conformation capped by a short $\alpha$-helix. Although found in all gonococcal zeta toxins, only the zeta homologue of Eikenella sp. NML01-A-086 contained a similar domain.
ngC_1 phosphorylates UNAM at the $4^{\prime}$-hydroxy group. Since we found UNAM to be a superb substrate in vitro compared to all other candidates which we identified by small metabolite extracts, we soaked UNAM into crystals and determined the structure of the complex. Indeed we observed a strong electron density for a UNAM molecule positioned in the active site of all four $n g \zeta_{-} 1$ polypeptide chains (Fig. 3c). To our surprise, Asp56, which most likely deprotonates the substrate before nucleophilic attack on the $\gamma$-phosphate group, is in hydrogen bonding distance to the $\mathrm{C4}^{\prime}$ $\mathrm{OH}$ group of the hexose moiety of UNAM, substantiating phosphorylation of this particular group. Indeed, by soaking purified, ng $\zeta$ 1 phosphorylated UNAM into our crystals we unambiguously showed that the phosphate group on UNAM was attached to the $\mathrm{C}^{\prime}{ }^{\prime}-\mathrm{OH}$ (Fig. 3d) and not to the $\mathrm{C}^{\prime}-\mathrm{OH}$ group atom, different to what has been described for the hitherto characterized zeta UNAG kinases ${ }^{21}$. We observed a number of interactions between ng $\zeta_{\_} 1$ and UNAM (Fig. 3c, d) and nearly all residues that form hydrogen bonds with UNAM are strictly conserved among homologues, but not in authentic UNAG-3' kinases (Supplementary Fig. 1). Most importantly, Asn75 and Lys59 form hydrogen bonds with the 1-carboxyethyl group of UNAM which could explain the preference of UNAM over UNAG by ng $\zeta$ _. Moreover, Arg181 and Arg175 form a positively charged patch in the active site counteracting the negatively 
charged phosphate groups. When comparing the configuration of UNAM bound to ng $\zeta_{-} 1$ with UNAG bound to $S$. pyogenes zeta toxin $^{21}$, we found a UDP-sugar binding mode to the active site that follows a rigid-body rotation by $180^{\circ}$ (Supplementary Fig. 7), causing that the $\mathrm{C} 4^{\prime}-\mathrm{OH}$ and not the $\mathrm{C}^{\prime}{ }^{\prime}-\mathrm{OH}$ group is located in close proximity to the catalytic important aspartic acid (Asp56 in ng $\zeta_{1} 1$ and Asp67 in $S$. pyogenes zeta toxin). To exclude that UNAG could be phosphorylated at a different site than UNAM we verified the specificity of $n g \zeta \_1$ towards the less preferred UNAG and confirmed phosphorylation of the $\mathrm{C}^{\prime}$ '-OH group of the $\mathrm{N}$-acetylglucosamine moiety by nuclear magnetic resonance (NMR) (Supplementary Fig. 8). In fact, no evidence accumulated from our NMR experiments that indicated any phosphorylation event other than that occurring at the $\mathrm{C}^{\prime}{ }^{\prime}-\mathrm{OH}$. Similarly, exclusive $\mathrm{C}^{\prime}-\mathrm{OH}$ phosphorylation was shown for streptococcal zeta toxins $^{21}$. Thus, no promiscuity towards the phosphorylation site is given and the observed phosphorylation event is not a side reaction in either case. In conclusion, $\operatorname{ng} \zeta_{-} 1$ performs a yet undescribed phosphorylation of the $\mathrm{C}^{\prime}-\mathrm{OH}$ groups of UDPsugars.

A non-discriminative blockade drains peptidoglycan synthesis. Our small metabolite extracts demonstrated no significant difference in the concentration of the three accumulating, phosphorylated UDP-sugars (Fig. 2a). Yet, our initial qualitative in vitro activity assays pointed to an increased activity of $\operatorname{ng} \zeta \_1$ for UNAM (Supplementary Fig. 4a). Thus, we wondered which factors determine to which extent each individual ng $\zeta \_1$ product accumulates in vivo. To this end, we first investigated substrate specificity of $\mathrm{ng} \zeta_{1} 1$ and characterized the Michaelis-Menten kinetics for the different identified substrates (Table 2; Supplementary Fig. 9). As expected from our initial, qualitative in vitro characterization, these measurements confirmed the apparent $K_{\mathrm{M}}$ for UNAM to be more than 10-fold smaller than for UNAG or UDP-glucose. Similarly, the determined apparent $k_{\text {cat }}$ for UNAM was more than 100-fold higher than for UNAG and UDP-glucose, respectively. This preference became even more prominent when comparing the catalytic efficiency. While this value is rather similar for UNAG and UDP-glucose, it is increased by a factor of approximately 1000 for UNAM, suggesting that UNAM-4P should be the predominant phosphorylated species also in vivo. Thus, we wondered whether UNAG-4P inhibits MurA activity similar as described for UNAG- $3 \mathrm{P}^{21}$ thereby preventing UNAM synthesis by MurA and MurB. This would lead to accumulating cellular levels of UNAG that can be phosphorylated by ng $\zeta_{-} 1$. Hence, we tested any potential inhibition of MurA by UNAG-4P. However, the reaction kinetics of UNAG phosphorylation by MurA remained unaffected when UNAG-4P was added in equimolar amounts to the natural substrate (Fig. 4a). UNAG-4P is rather a dead-end product and cannot be used by MurA anymore. Similarly, MurB activity was also not affected by the presence of any EP-UNAG-4P and it was not reduced to UNAM-4P by the enzyme (Fig. 4a). Importantly, also MurC activity remained the same and the enzyme could not use UNAM-4P as

Table 2 Michaelis-Menten parameters of ng $\zeta_{-} 1$ activity

\begin{tabular}{|c|c|c|c|}
\hline & $K_{M}(\mathbf{m M})$ & $k_{\text {cat }}\left(s^{-1}\right)$ & $\begin{array}{l}k_{\text {cat }} / K_{M}\left(\mathrm{mM}^{-1} \mathrm{~s}\right. \\
\text { s. }\end{array}$ \\
\hline UNAM $_{(4 \text { mM ATP })}$ & $0.23 \pm 0.02$ & $200 \pm 7$ & 880 \\
\hline $\mathrm{UNAG}_{(4 \mathrm{mM} \text { ATP })}$ & $2.8 \pm 0.3$ & $1.72 \pm 0.05$ & 0.6 \\
\hline UDP-glucose $_{(4 \mathrm{mM} \text { ATP })}$ & $6.4 \pm 0.7$ & $0.71 \pm 0.03$ & 0.1 \\
\hline $\operatorname{ATP}_{(1 \mathrm{mM}}$ UNAM $)$ & $2.6 \pm 0.4$ & $280 \pm 16$ & 110 \\
\hline $\operatorname{ATP}_{(20} \mathrm{mM}$ UNAG) & $0.34 \pm 0.02$ & $1.76 \pm 0.02$ & 5.2 \\
\hline $\operatorname{ATP}_{(20 \mathrm{mM} \text { UDP-glucose })}$ & $0.31 \pm 0.05$ & $0.51 \pm 0.02$ & 1.7 \\
\hline
\end{tabular}

potential substrate (Fig. 4a). Apparently, none of these enzymes can use their phosphorylated substrates anymore and thus cannot channel any ngک_1-phosphorylated peptidoglycan precursor
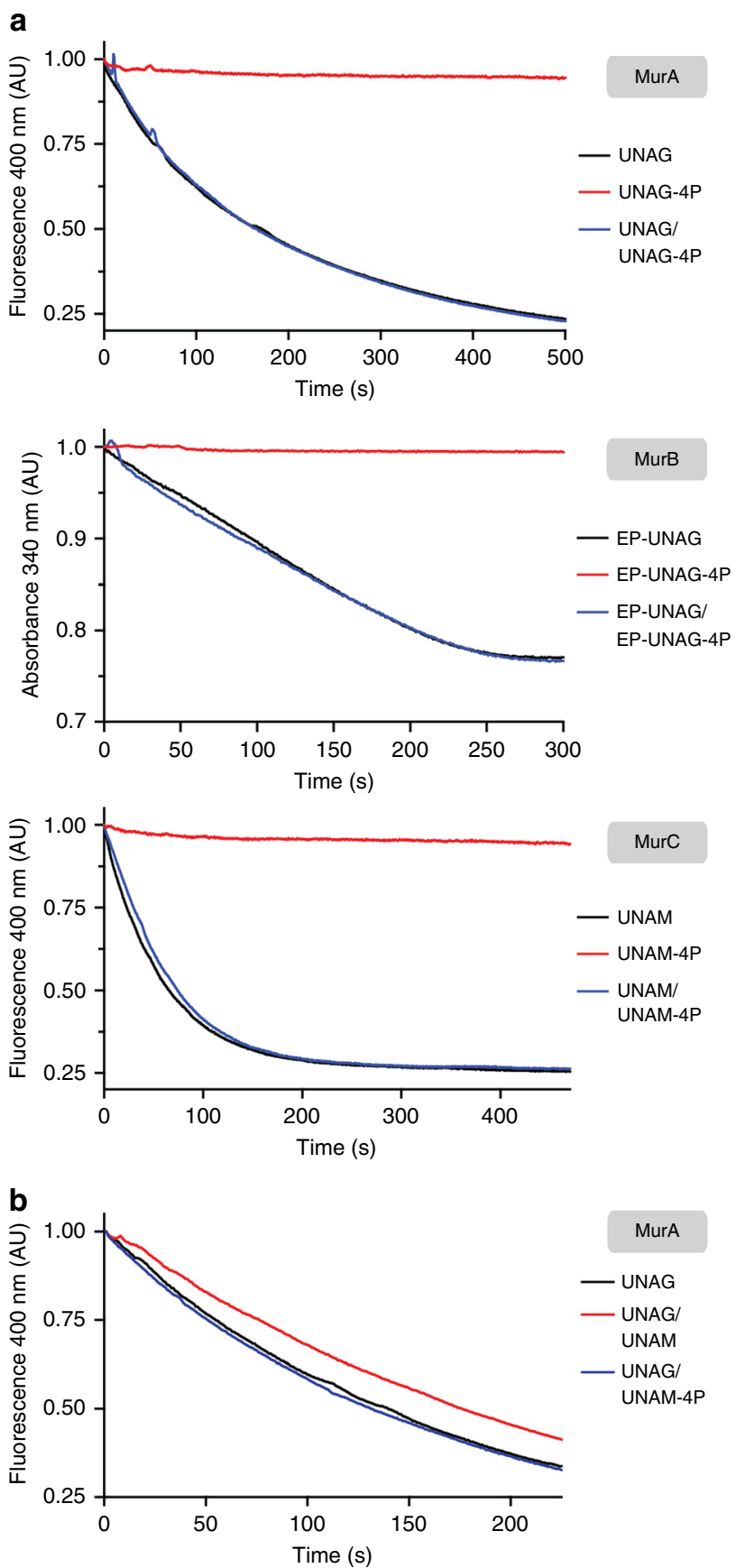

Fig. 4 Effect of ng $\zeta_{-} 1$ products on enzymes involved in early peptidoglycan synthesis. a Effect of in vitro phosphorylated ng $\zeta_{-} 1$ products on the activity of the first three enzymes of the peptidoglycan synthesis, MurA

(monitoring phosphate release), MurB (monitoring NADPH oxidation) and MurC (monitoring phosphate release). In vitro reactions were perfomed in presence of either the native non-phosphorylated substrate (black; $50 \mu \mathrm{M}$ UNAG, $30 \mu M$ EP-UNAG or $50 \mu M$ UNAM), the phosphorylated form (red; $50 \mu \mathrm{M}$ UNAG-4P, $30 \mu \mathrm{M}$ EP-UNAG-4P, $50 \mu \mathrm{M}$ UNAM-4P), or both at equimolar concentrations (blue). Reactions were started upon addition of either $0.25 \mu \mathrm{M}$ MurA, $50 \mathrm{nM}$ MurB, or $2 \mu \mathrm{M}$ MurC (time $0 \mathrm{~s}$ ). b Effect of UNAM and UNAM-4P on MurA activity. MurA activity assay using $100 \mu \mathrm{M}$ UNAG (black) performed in the presence and absence of additional $100 \mu \mathrm{M}$ UNAM-4P (blue) or UNAM (red) 


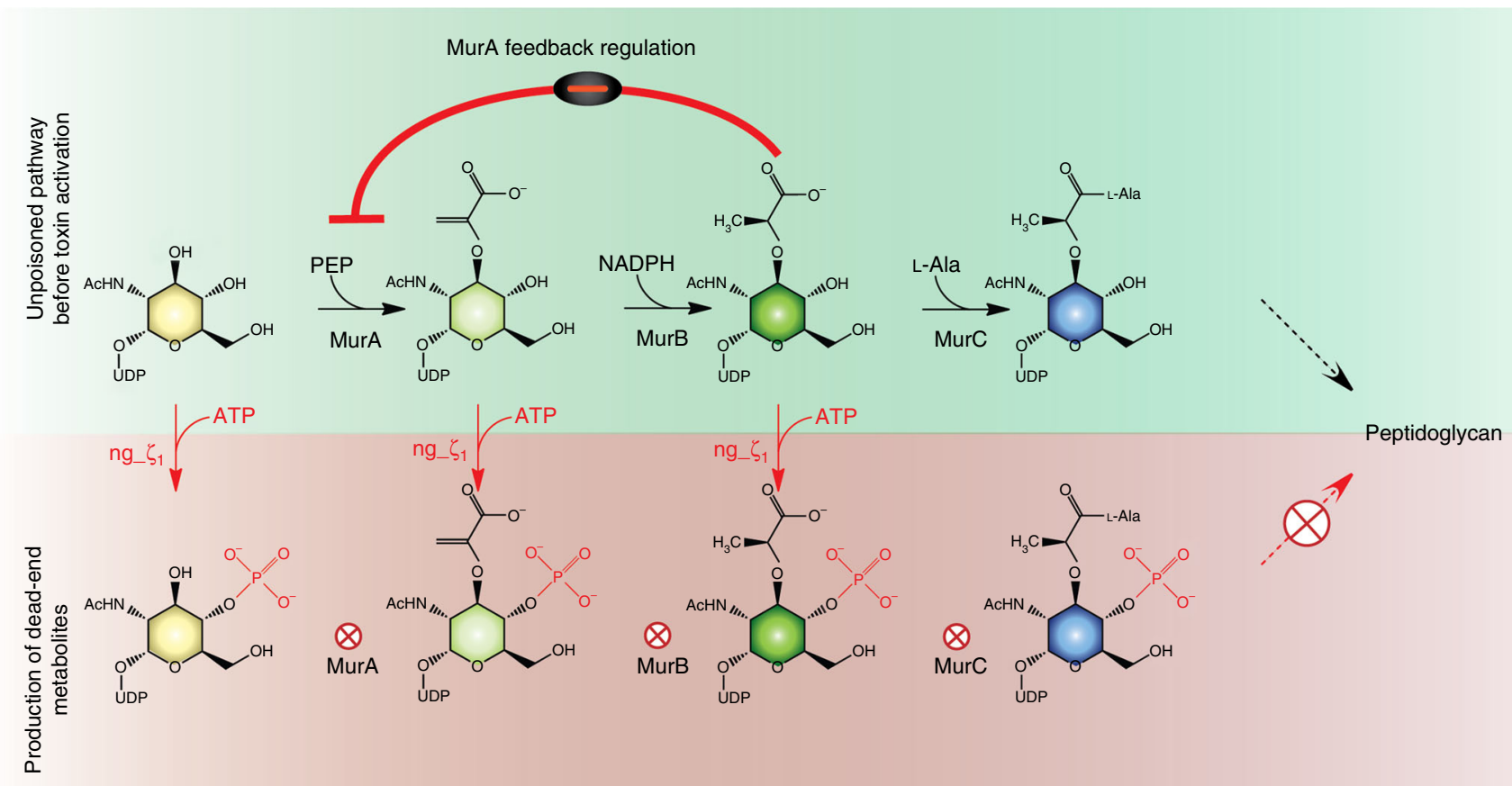

Fig. 5 ng $\zeta_{-} 1$ drains precursors from peptidoglycan synthesis at multiple stages. Under normal conditions cytosolic levels of UNAM regulate peptidoglycan synthesis by a negative feedback loop inhibiting MurA. In contrast, once ng $\zeta_{-} 1$ becomes active, MurA, MurB, and MurC are depleted from their substrates. All phosphorylated precursors are dead-end metabolites; however, none of them seems to directly inhibit any enzyme of early peptidoglycan synthesis

downstream into the pathway. Ultimately, we also tested whether UNAM-4P can inhibit MurA and thus would still mimic the generic feedback loop in early peptidoglycan synthesis ${ }^{40}$. However, this seems also not to be the case as we could not observe such an inhibition by UNAM-4P (Fig. 4b).

In conclusion, our findings strongly suggest that the cellular substrate concentrations are the key determinants for $n g \zeta_{-} 1$ activity. As proof of principle, we tested EP-UNAG, one of the least abundant precursors in cytosolic peptidoglycan synthesis, and observed robust phosphorylation in vitro already after $30 \mathrm{~min}$ of incubation (Supplementary Fig. 10). Yet, we did not observe EP-UNAG-4P in our small metabolite extracts (Fig. 2a) although the resolution of the HPLC-separation would allow for distinguishing any potentially formed EP-UNAG-4P from all other accumulating species (Supplementary Fig. 11). In conclusion these results strongly suggest that the concentration of the accumulating species is dictated by the cytosolic levels and the toxic phenotype of $n g \zeta_{-} 1$ is due to draining all enzymes of early peptidoglycan synthesis from their substrates (Fig. 5).

\section{Discussion}

We have studied the gonococcal $n g \zeta \_1$ as the paradigm for a hitherto unknown class of abundant zeta kinases that are wired topologically different when compared to previously characterized zeta toxins of Gram-positive bacteria. Thereby, we identified a yet undescribed enzymatic activity. This proteobacterial zeta toxin phosphorylates UDP-activated sugar species at the $\mathrm{C}^{\prime}{ }^{\prime}-\mathrm{OH}$ group of the hexose moiety which eventually causes a lytic phenotype. The toxic activity is inhibited by co-expression of nge_1 antitoxin, corroborating that the $n g \varepsilon_{-} 1 / n g \zeta_{-} 1$ locus encodes for a toxin/antitoxin pair. As expected for a bona-fide type II TA system, we demonstrated protein-protein complex formation between nge_1 and ng $\zeta \_1$, which assemble into a heterodimeric complex.
In contrast to previously studied epsilon antitoxins, the nge_1 wraps around $n g \zeta \_1$ in an extended conformation and does not protrude into the ATP binding site. In this respect, nge_1 is more similar to the majority of antitoxins of type II TA systems, such as ParD, RelB, MazE and HigA. For these antitoxins an unfolded structure of the unbound protein was either shown or speculated to cause increased proteolytic instability than when complexed with the cognate toxin ${ }^{41}$. This intrinsic instability is thought to be important in the regulation of toxin activity in the cell ${ }^{41}$. Furthermore, the three-dimensional structure revealed a topological rewiring that seems to distinguish the $\mathrm{C} 4^{\prime}-\mathrm{OH}$ phosphorylating zeta toxin from the streptococcal $\mathrm{C}^{\prime}-\mathrm{OH}$ phosphorylating zeta subfamily.

Similar to its streptococcal counterparts ${ }^{21}, \operatorname{ng} \zeta \_1$ was shown to phosphorylate peptidoglycan precursors in vitro and in vivo and cell lysis is a consequence of impairment of peptidoglycan synthesis. However, ng $\zeta \_1$ uses a broader substrate spectrum and phosphorylates UNAG as well as UNAM and UDP-glucose at their $\mathrm{C}^{\prime}$ '-OH group. Michaelis-Menten kinetics for the different substrates reveal that $n g \zeta \_1$ has highest catalytic efficiency for UNAM. This leads to a significant accumulation of UNAM-4P in the cell, a dead-end metabolite that cannot be modified by MurC. However, contrasting the reduced catalytic efficiency for UNAG in vitro, considerable amounts of UNAG-4P were detected in vivo. As it is the case for UNAM-4P, also UNAG-4P accumulates as UNAG is also turned into an unsuitable substrate for MurA. In conclusion, both dead-end products of ng $\zeta_{-}$, UNAG$4 \mathrm{P}$ and UNAM-4P, drain MurA and MurC from their substrates (Fig. 5).

We showed that the cellular accumulation of UNAG-4P and UNAM-4P is not due to any inhibition of the Mur enzyme cascade but rather is determined by cellular concentrations of the individual precursors. While UNAM is present at an intracellular concentration of only 30-60 $\mu \mathrm{M}$ in $E$. coli ${ }^{42}$, the concentration of UNAG is approximately ten-fold higher $(100-500 \mu \mathrm{M})^{43-45}$. 
Therefore UNAG-4P accumulated in vivo although it is only slowly converted by ng $\zeta \_1$. In fact, EP-UNAG, which we could not detect in vivo as accumulating phosphorylated species but is phosphorylated in vitro by $\operatorname{ng} \zeta_{-} 1$, is less abundant by a factor of 100 compared to $\mathrm{UNAG}^{43}$. Similarly, in vivo accumulation of the even less preferred UDP-glucose is most likely due to its approximately fifty-fold higher concentration $(1.5-1.8 \mathrm{mM})^{46}$. Altogether, formation of these phosphorylated species depletes bacteria from precursors required for de novo synthesis of cell wall components (Fig. 5).

Although our data imply that the drain of the early steps in peptidoglycan synthesis catalysed by MurA, MurB and MurC is very effective, it seems plausible that the addition of a phosphate group to the $\mathrm{C} 4$ ' $-\mathrm{OH}$ group will inhibit further downstream processes as well. A non-redundant cascade of enzymes, namely MurC to MurF, subsequently adds an amino acid stem to UNAM, resulting in UNAM-pentapeptide ${ }^{27}$. MraY anchors the UNAMpentapeptide to cell membrane forming undecaprenyl-pyrophosphoryl-MurNAc-pentapeptide, known as lipid I. Finally, lipid I is condensed with the $\mathrm{Cl}^{\prime}$-OH group of UNAG via a $B-(1-4)$-glycosidic bond by MurG, producing lipid II. This terminates the cytosolic steps of peptidoglycan synthesis as lipid II is flipped either into the periplasmic or extracellular space where transglycosylases catalyze the formation of alternating glycan chain strands. Together with peptide bridges this results in the meshlike structure of the peptidoglycan layer, which confers rigidity to the cell envelope. Additional inhibitory events are for instance likely at the stage of lipid II formation. MurG which forms the glycosidic bond between a UNAG molecule and lipid I to generate lipid II is highly stereo selective and was shown to exclude the epimer UDP- $N$-acetylgalactosamine, which just differs in the stereochemistry of the $\mathrm{C}^{\prime}-\mathrm{OH}^{47}$. Accordingly, UNAG-4P will most likely also not be accepted by MurG and ng $\zeta_{-} 1$ therefore will also impair lipid II formation. Although this requires experimental validation, any phosphorylated lipid II would in turn terminate periplasmic glycan strand synthesis by blocking 1-4 glycosidic bond formation of transglycosylases.

Although our study focused on the effect of $\operatorname{ng} \zeta_{-} 1$ on peptidoglycan synthesis, formation of UNAG-4P but also that of UDPglucose-4P will additionally affect the synthesis of other cell wall components such as lipopolysaccharides (LPS), colanic acids, teichoic acids and the capsule. Similar to its unique role in peptidoglycan synthesis, UNAG is also the central precursor for lipid A (also known as endotoxin) synthesis, the membrane anchor of LPS of Gram-negative bacteria ${ }^{48}$. The highly conserved UDP-Nacetylglucosamine acyltransferase LpxA, that commits the first step of lipid A synthesis, binds UNAG in a narrow active site ${ }^{49}$, and thus likely will not accept UNAG-4P as substrate, similar as we demonstrated for MurA. While lipid A is highly conserved in Gram-negative bacteria, the composition of the residual LPS is much more diverse and strain specific ${ }^{50}$. Yet, D-glucose is a universally incorporated in many of the latter parts of LPS and thus it is tempting to speculate that formation of UDP-glucose-4P might interfere with their synthesis.

Apparently, zeta toxins encoded by Gram-negative and Grampositive bacteria do not group into a single uniform kinase family but form at least two functionally and structurally differentiated subfamilies. Although similar in their active site architectures, these toxic enzymes vary in their selectivity and specificity for UDP-activated sugar species, but also in the mechanism by which they interfere with vital cellular processes. On one hand, streptococcal toxins stall the first committed step of peptidoglycan synthesis by inhibition, as formation of UNAG-3P by PezT leads to the accumulation of a strong inhibitor of MurA ${ }^{21}$. When a certain level of UNAG-3P is reached the bacterial peptidoglycan synthesis will halt, which can only be relieved by the breakdown of the inhibitor UNAG-3P. On the other hand, ng $\zeta_{-} 1$ depletes peptidoglycan and LPS from substrates molecules by forming non-inhibiting, dead-end metabolites and interferes at multiple stages in the pathway. Such a depletion mechanism is in constant competition with the de novo synthesis of cell wall components. This potentially allows a tuning of the peptidoglycan synthesis rates, which gradually decreases with an increase of ng $\zeta_{-} 1$ activity. It seems plausible, that the different mechanisms reflect an adaptation of the zeta toxins to the peptidoglycan and cell wall structure of bacteria. Whereas the thin periplasmic peptidoglycan mesh in Gram-negative bacteria is very sensitive to changes in its synthesis, the thick outer-membrane peptidoglycan of Grampositive bacteria may tolerate or even require stronger interference. Zeta toxins might differ in their rates and mechanisms of peptidoglycan synthesis inhibition to still allow recovery once the antitoxin is replenished within a certain frame before cell lysis occurs.

Although experimental evidence has not accumulated for Gram-negative zeta toxins so far, their Gram-positive homologues seem to play a role in bacterial pathogenicity as they have been connected with increased virulence ${ }^{51}$, reduced sensitivity to antibiotics and competence ${ }^{35,52}$, and stable inheritance of mobile genetic elements ${ }^{53-55}$. It seems plausible that ng $\zeta_{-} 1$ in Gramnegative bacteria will also have an impact on pathogenicity. $\mathrm{Ng} \zeta \_1$ impairs the synthesis of two essential cell wall components, peptidoglycan and LPS, which are common virulence factors of Gram-negative bacteria. LPS and fragments thereof such as lipid A as well as fragments of peptidoglycan are established immunoactive molecules and the innate immune system of any potential host is specialized in recognizing them. Noteworthy, $N$. gonorrhoea releases a large amount of peptidoglycan fragments such as the Tracheal cytotoxin into the environment ${ }^{56}$, which were shown to be involved in pathogenicity ${ }^{57}$ and by stalling de novo synthesis of peptidoglycan, ng $\zeta \_1$ will have an impact on that. On the other side, by interfering with lipopolysaccharide synthesis, ng $\zeta_{1} 1$ potentially may also modulate endotoxin release of pathogenic Gram-negative bacteria and may also be involved in phase variation of the lipopolysaccharide composition to evade the host immune system ${ }^{58}$.

In conclusion, this study showed how a Gram-negative epsilon zeta TA system modifies essential cell wall components and thereby interferes with vital cellular processes. Doubtless, the $n g \varepsilon_{-} 1$ / $n g \zeta \_1$ locus encodes for a plasmid-encoded functional TA system that per se has the potential to support stable plasmid maintenance. However, given that $n g \zeta_{-} 1$ toxicity interferes with the synthesis of pathogenicity-related cellular compounds at multiple levels, it is tempting to speculate that in addition to its influence on genome plasticity, the nge_1/ng $\zeta_{-} 1$ might modulate Gram-negative bacteria's pathogenicity; a hypothesis which urges for further detailed studies.

\section{Methods}

Cloning and protein expression for purification. Cloning of the individual expression constructs was performed according to standard procedures. The sequence of each individual construct was verified by DNA sequencing. A detailed description for the cloning procedure is given in the Supplementary Methods section and in Supplementary Table 2.

For protein purification, individual constructs were transformed into $E$. coli strain BL21(DE3)-RIL cells and bacterial cultures were grown in LB-medium with the appropriate antibiotics to an $\mathrm{OD}_{600}$ of 0.5 at $37^{\circ} \mathrm{C}$. Subsequently, the cell cultures were transferred to $20^{\circ} \mathrm{C}$ and protein expression was induced by addition of $0.5 \mathrm{mM}$ isopropyl- $\beta$-D-thiogalactopyranoside. For production of selenomethionine labeled protein, pET28b_nge_1/ng乙_1(K115A) transformed cells were grown in an amino acid supplemented minimal medium ${ }^{59}$. Cells were harvested by centrifugation and cell pellets were suspended in their appropriate $\mathrm{Ni}$ NTA equilibration buffers (see Supplementary information). Cell walls were broken by sonication and the supernatant was cleared by centrifugation before loading onto the first column. All proteins used in this study were purified by standard chromatographic procedures which are described in detail in the 
Supplementary Information. Protein homogeneity was monitored during all steps by Coomasssie stained SDS-PAGE. Protein aliquots were flash-frozen and stored at $-80^{\circ} \mathrm{C}$

Phenotype characterization of nge_1/ng $\boldsymbol{C}_{-} \mathbf{1}$. Cell lysis accompanied by breakdown of the osmotic barrier was monitored by measuring cell growth at $\mathrm{OD}_{600}$ and fluorescence upon propidium iodide (Sigma-Aldrich, St. Louis, USA) influx into ng $\zeta$ 1 poisoned E. coli C41(DE3) cells which are commonly known to tolerate toxin expression much better than BL21(DE3)-RIL. Yet, cells needed to be cotransformed with pET28b_nge_1 and either pBAD_ng $\zeta \_1$ or $p B A D \_n g \zeta \_1$ (K115A), respectively, for stable maintenance of toxic ng $\zeta \_1$ encoding plasmids. However, promotor leakage was sufficient for stable maintenance during all experiments and nge_1 remained uninduced during all experiments. Overnight cultures were inoculated in LB-medium containing ampicillin and $0.3 \%(w / v)$ glucose from single colonies and grown at $37^{\circ} \mathrm{C}$. After 1:10 dilution, cell growth was resumed to an $\mathrm{OD}_{600}$ of 0.2 . Subsequently, this cell culture was diluted with an equal volume of LB medium supplemented with $0.1 \mathrm{mg} / \mathrm{ml}$ propidium iodide and $0.2 \%(w / v)$ L- $(+)$-arabinose for $n g \zeta \_1$ or $n g \zeta \_1(\mathrm{~K} 115 \mathrm{~A})$ expression. Two hundred microliter of these mixtures were transferred into a 96-well plate (Corning 3651, Corning Inc, Corning, USA) and $\mathrm{OD}_{600}$ and propidium iodide fluorescence (excitation: $520 \mathrm{~nm}$, emission: $620 \mathrm{~nm}$ ) was monitored over $90 \mathrm{~min}$ using a Varioscan Flash Multimode Reader (Thermo Fisher Scientific, Waltham, USA). Cell cultures for phase contrast and fluorescence microscopy experiments were prepared following the same protocol. Live/dead staining was performed using the LIVE/DEAD BacLight bacterial viability kit (Molecular Probes, Carlsbad, USA).

Analysis of low-molecular-weight metabolite extracts. Low-molecular-weight metabolite extraction and analysis was performed similarly as previously described $^{21}$. Briefly, E. coli C41(DE3) cells harboring pET28b(nge_1) and either pBAD_ng $\zeta \_1$ or pBAD_ng $\zeta \_1(\mathrm{~K} 115 \mathrm{~A})$ were grown in $500 \mathrm{ml}$ of LB-medium supplemented with ampicillin to an $\mathrm{OD}_{600}$ of 0.3 , protein expression was induced upon addition of $0.2 \%(w / v) \mathrm{L}-(+)$-arabinose and cells were harvested by centrifugation $20 \mathrm{~min}$ post-induction. The cell pellets were resuspended in $20 \mathrm{ml}$ icecold $80 \%(v / v)$ aqueous acetonitrile and incubated for $30 \mathrm{~min}$ on ice with regular agitation. The supernatant was cleared by centrifugation and the solvent was evaporated. Aliquots were diluted with deionized water, cleared by filtration and adjusted to a common $\mathrm{A}_{260}$ of $20 \mathrm{AU}$. Thirty microliter of sample was applied to a Partisil-5 SAX RACII column (Whatman plc, Maidstone, UK) equilibrated with 5 $\mathrm{mM} \mathrm{KH} \mathrm{PO}_{4}$. Bound metabolites were separated in a linear gradient to $500 \mathrm{mM}$ $\mathrm{KH}_{2} \mathrm{PO}_{4}$. Fractions containing accumulating UDP-sugars were pooled, bound to a MonoQ 5/50 GL column equilibrated with deionized water and eluted in a linear gradient to $1 \mathrm{M}$ ammonium acetate $\mathrm{pH} 8.0$ (32 column volumes (CV)). Solvent and volatile compounds were removed by repeated evaporation and purified compounds were dissolved in deionized water, analyzed with a Bruker maXis II mass spectrometer (Bruker Corporation, Billerica, USA) and fragmented by collisioninduced dissociation.

Oligomeric state determination of the $\mathbf{n g} \varepsilon_{-} \mathbf{1} / \mathbf{n g} \zeta_{-} \mathbf{1}$ complex. The oligomeric state of the ngE_1/ng $\zeta_{-} 1$ protein complex was determined by multi-angle light scattering (Wyatt, Santa Barbara, USA) coupled to size-exclusion chromatography using a Superdex200 10/300 GL column (GE Healthcare, $50 \mathrm{mM}$ MES-NaOH pH 6.0 and $200 \mathrm{mM} \mathrm{NaCl}$ ). Forty microliter of either nge_1/ng $\zeta_{-} 1$ protein complex or protein standard mixture (Bio-Rad, Hercules, USA) were injected and the recorded data were analyzed using the ASTRA software (Wyatt).

Synthesis and purification of UDP-sugars. UNAM was prepared through successive enzymatic conversion of UNAG by MurA and MurB. To avoid potential inhibition of MurA by UNAM ${ }^{40}, 300 \mu \mathrm{M}$ UNAG was first converted to EP-UNAG by MurA. Therefore, $1 \mu \mathrm{M}$ MurA was mixed with $1 \mathrm{mM}$ phosphoenolpyruvate (PEP) and $400 \mu \mathrm{M}$ NADPH in a buffer composed of $50 \mathrm{mM}$ Tris- $\mathrm{HCl}, \mathrm{pH} 8.0,50$ $\mathrm{mM} \mathrm{NaCl}$ and $10 \mathrm{mM} \mathrm{KCl}$. After $3 \mathrm{~h}$ incubation at room temperature, $0.5 \mu \mathrm{M}$ MurB were added and the reaction was further incubated overnight. The reaction mixture was diluted in deionized water (1:2), loaded onto a MonoQ 10/100 GL column equilibrated with deionized water. Bound residual UNAG and NADP were removed by washing the column with $300 \mathrm{mM}$ ammonium acetate $\mathrm{pH} 8.0$ and UNAM was eluted with $350 \mathrm{mM}$ of ammonium acetate $\mathrm{pH}$ 8.0. Fractions containing UNAM were pooled and concentrated by evaporation. Finally, UNAM was desalted by size exclusion chromatography using a Superdex75 10/300 GL column equilibrated with deionized water. UNAM containing fractions were pooled and concentrated by evaporation.

Synthesis of EP-UNAG was performed similar to the production of UNAM but neither MurB nor NADPH was included in the reaction mixture. The reaction was incubated for $2.5 \mathrm{~h}$ at room temperature and EP-UNAG was purified by anion exchange and size exclusion chromatography as described for UNAM.

For production of UNAM-4P, $300 \mu \mathrm{M}$ UNAM was incubated with $10 \mathrm{nM} \mathrm{ng} \zeta \_1$ in preparation buffer $(50 \mathrm{mM}$ MES-NaOH pH $6.0,200 \mathrm{mM} \mathrm{NaCl}, 0.5 \mathrm{mM}$ EDTA, $14 \mathrm{mM} \mathrm{KCl}$ and $2 \mathrm{mM} \mathrm{PEP}$ ) supplemented with $4 \mathrm{mM} \mathrm{MgCl}_{2}$ and $1 \mathrm{mM} \mathrm{ATP}$. For recycling of ATP from ADP, $7.2 \mathrm{U}$ of pyruvate kinase $(\mathrm{PK}) / 10.8 \mathrm{U}$ of lactate dehydrogenase $(\mathrm{LDH})$ were included in the reaction. After incubation at $25^{\circ} \mathrm{C}$ for
$6 \mathrm{~h}$, the reaction mixture was diluted in deionized water and loaded onto a MonoQ 5/50 GL column equilibrated with deionized water. Bound ATP was eluted by washing the column with $30 \mathrm{mM} \mathrm{MgCl}$. Subsequently, the column was washed in four steps with water, $1 \mathrm{mM}$ EDTA $\mathrm{pH} 8.0$, water and $170 \mathrm{mM}$ ammonium bicarbonate, $\mathrm{pH}$ 8.0. Pure UNAM-4P was eluted with $1 \mathrm{M}$ ammonium bicarbonate, $\mathrm{pH}$ 8.0. Concentrating and desalting of UNAM-4P was performed similar as described for UNAM and EP-UNAG.

The enzymatic conversion of $250 \mu \mathrm{M}$ EP-UNAG to EP-UNAG-4P by ng $\zeta_{1} 1$ (1 $\mu \mathrm{M})$ was performed in preparation buffer supplemented with $1 \mathrm{mM} \mathrm{MgCl}_{2}, 0.5$ mM ATP and 0.6 U PK/0.9 U LDH. Phosphorylated EP-UNAG was loaded onto a Mono Q 5/50 GL column equilibrated with water and eluted in a gradient of $60 \mathrm{CV}$ to $1 \mathrm{M}$ ammonium acetate $\mathrm{pH}$ 8.0. Fractions containing EP-UNAG-4P were pooled and concentrated by evaporation. For quantitative removal of ammonium acetate, the pellet of EP-UNAG-4P was re-dissolved in pure water and re-concentrated twice. The correct identity for the different UDP-activated sugar species was verified by ESI-MS and the final concentration of was determined spectroscopically $\left(\varepsilon_{260}=10.100 \mathrm{~cm}^{-1} \mathrm{M}^{-1}\right)^{60,61}$.

Chromatographic ng $\zeta \_1$ phosphorylation assays. Substrate phosphorylation by ng $\zeta \_1$ was analyzed using a chromatographic assay. Two hundred and fifty micromolar EP-UNAG, UDP-glucose or UNAG and $0.5 \mathrm{mM}$ ATP were mixed in

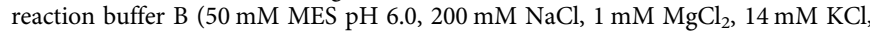
$2 \mathrm{mM}$ PEP, $0.6 \mathrm{U}$ PK and $0.9 \mathrm{U} \mathrm{LDH})$ in a total volume of $180 \mu \mathrm{l}$. Reactions were started by addition of $1 \mu \mathrm{M}$ ng $\zeta \_1$ and incubated at $25^{\circ} \mathrm{C}$ for different time points (5 min, 3, 12, and $24 \mathrm{~h}$ ). A reaction lacking ng $\zeta \_1$ was used as a control. The progression of the reaction was followed via anion exchange chromatography. The mixture was applied to MonoQ 5/50 GL column equilibrated with deionized water After an initial isocratic elution with $200 \mathrm{mM}$ ammonium acetate $\mathrm{pH}$ 8.0, a linear gradient to $1 \mathrm{M}$ ammonium acetate was performed (33 CV for UDP-glucose and UNAG, $60 \mathrm{CV}$ for EP-UNAG). The specific retention volume and characteristic 260:280 ratio were used to identify the nucleotide species.

NMR characterization of UNAG-4P. UNAG-4P was dissolved in $99.9 \% \mathrm{D}_{2} \mathrm{O}$ at a concentration of $6 \mathrm{mg} / \mathrm{ml}$ and spectra were recorded at $25^{\circ} \mathrm{C}$ using a Varian 500 NMR system spectrometer (Agilent). NMR experiments were processed and analyzed using the MestReNova 10.0 (MestreLab Research) software. Atom names and assignment is given in Supplementary Fig. 5 .

Signal assignment of ${ }^{1} \mathrm{H}$ NMR experiments $\left(500 \mathrm{MHz},{ }^{1} \mathrm{H}_{-}{ }^{1} \mathrm{H}-\mathrm{COSY}, \mathrm{D}_{2} \mathrm{O}\right): \delta$ $=7.98\left(\mathrm{~d}, 1 \mathrm{H},{ }^{3} J_{\mathrm{HH}}=8.2 \mathrm{~Hz}, \mathrm{H}-\mathrm{U} 6\right), 6.0-5.98\left(\mathrm{~m}, 2 \mathrm{H}, \mathrm{H}-\mathrm{U} 5, \mathrm{H}-1^{\prime}\right), 5.53(\mathrm{dd}, 1 \mathrm{H}$, $\left.{ }^{3} J_{\mathrm{HH}}=7.3 \mathrm{~Hz},{ }^{3} J_{\mathrm{HP}}=3.2 \mathrm{~Hz}, \mathrm{H}-1\right), 4.40-4.37\left(\mathrm{~m}, 2 \mathrm{H}, \mathrm{H}-2^{\prime}, \mathrm{H}-3^{\prime}\right), 4.30(\mathrm{~m}, 1 \mathrm{H}, \mathrm{H}-$ $\left.4^{\prime}\right), 4.28-4.25$ (m, 1H, H-5'a), 4.22-4.18 (m, 1H, H-5'b), 4.08-3.97 (m, 4H, H-2, H3, H-4, H-5), 3.90-3.84 (m, 2H, H-6a, H-6b), 2.09 (s, 3H, H-8) ppm.

Assignment of ${ }^{13} \mathrm{C}$ NMR experiments (152.7 MHz, APT, HSQC, $\left.\mathrm{D}_{2} \mathrm{O}\right): \delta=$ $174.63(\mathrm{C}, \mathrm{C}=\mathrm{O}), 166.14(\mathrm{C}, \mathrm{C}=\mathrm{O}), 151.72(\mathrm{C}, \mathrm{C}=\mathrm{O}), 141.55(\mathrm{CH}, \mathrm{C}-\mathrm{U} 6), 102.59$ $(\mathrm{CH}, \mathrm{C}-\mathrm{U} 5), 94.03\left(\mathrm{CH}, J_{\mathrm{CP}}=6.2 \mathrm{~Hz}, \mathrm{C}-1\right), 88.38\left(\mathrm{CH}, \mathrm{C}-1^{\prime}\right), 83.16\left(\mathrm{CH}, J_{\mathrm{CP}}=9.0\right.$ $\left.\mathrm{Hz}, \mathrm{C}-4^{\prime}\right), 73.71\left(\mathrm{CH}, \mathrm{C}-3^{\prime}\right), 73.25\left(\mathrm{CH}, J_{\mathrm{CP}}=4.7 \mathrm{~Hz}, \mathrm{C}-5\right), 72.03\left(\mathrm{CH}, J_{\mathrm{CP}}=5.7\right.$ $\mathrm{Hz}, \mathrm{C}-4), 70.41(\mathrm{CH}, \mathrm{C}-3), 69.57\left(\mathrm{CH}, \mathrm{C}-2^{\prime}\right), 64.90\left(\mathrm{CH}_{2}, J_{\mathrm{CP}}=6.2 \mathrm{~Hz}, \mathrm{C}-5^{\prime}\right), 60.11$ $\left(\mathrm{CH}_{2}, \mathrm{C}-6\right), 53.35\left(\mathrm{CH}, J_{\mathrm{CP}}=8.5 \mathrm{~Hz}, \mathrm{C}-2\right), 22.00\left(\mathrm{CH}_{3}, \mathrm{C}-8\right) \mathrm{ppm}$.

Assignment of ${ }^{31} \mathrm{P}$ NMR decoupling experiments $\left(202.4 \mathrm{MHz}, \mathrm{D}_{2} \mathrm{O}\right): \delta=0.91$ $(\mathrm{s}, \mathrm{P}-4),-11.46\left(\mathrm{~d}, J_{\mathrm{PP}}=19.7 \mathrm{~Hz}, \mathrm{P}-5^{\prime}\right),-13.16\left(\mathrm{~d}, J_{\mathrm{PP}}=20.0 \mathrm{~Hz}, \mathrm{P}-1\right) \mathrm{ppm}$.

Structure determination. Crystals of wild type nge_1/ng $\zeta_{-} 1$ or selenomethionine labelled nge_1/ng $\zeta \_1(\mathrm{~K} 115 \mathrm{~A})$ protein complex were grown at a concentration of $22 \mathrm{mg} / \mathrm{ml}$ using a sitting drop vapor diffusion setup. Best crystals grew as stacked plates using a reservoir solution of $100 \mathrm{mM}$ sodium citrate $\mathrm{pH} 4.5$ and $1.8 \mathrm{M}$ $\left(\mathrm{NH}_{4}\right)_{2} \mathrm{SO}_{4}$. Crystals were transferred to a solution containing $100 \mathrm{mM}$ sodium citrate $\mathrm{pH} 4.5,2 \mathrm{M}\left(\mathrm{NH}_{4}\right)_{2} \mathrm{SO}_{4}$ and $20 \%(v / v)$ propylene glycol and flash cooled in liquid nitrogen. UNAM or UNAM-4P at a concentration of $20 \mathrm{mM}$ were added to the cryo-protectant and incubated for $10 \mathrm{~min}$ during soaking experiments.

Se-SAD and native diffraction data were collected at the Swiss Light Source X10SA beamline and processed with the XDS software package ${ }^{62}, 5 \%$ of the reflection were randomly selected for calculation of $R_{\text {free }}$ and inherited to all datasets. Initial phases were obtained using the SHELXC and SHELXD ${ }^{63}$ from SeSAD on nge_1/ng $\zeta \_1(\mathrm{~K} 115 \mathrm{~A})$ protein complex crystals. Phases from the Sesubstructure obtained from SHELXD were improved using Phaser ${ }^{64}, \operatorname{Parrot}^{65}$ and $\mathrm{DM}^{66}$. An initial model was built using $\mathrm{Coot}^{67}$ and refined using the simulated annealing protocol of $\mathrm{CNS}^{68}$. Subsequently, the model was improved in iterative cycles of manual building in Coot and refinement using Refmac ${ }^{69}$. Final structure validation was performed using MolProbity ${ }^{70}$. Figures were prepared using PYMOL $^{71}$

ngל_1 kinase activity assays. Phosphorylation of different UDP-activated sugar species by ng $\zeta \_1$ was monitored using a coupled spectroscopic assay in which formation of $\mathrm{ADP}$ is coupled to consumption of $\mathrm{NADH}^{72}$. Conversion of $\mathrm{NADH}$ to $\mathrm{NAD}^{+}$was monitored spectroscopically at $340 \mathrm{~nm}$ (Jasco V650, Jasco, Mary's Court, USA). All reactions were performed in assay buffer (50 mM MES-NaOH pH $6.0,200 \mathrm{mM} \mathrm{NaCl}, 1 \mathrm{mM}$ EDTA, $6 \mathrm{mM} \mathrm{MgCl}, 14 \mathrm{mM} \mathrm{KCl}, 1 \mathrm{mM}$ PEP, $0.25 \mathrm{mM}$ $\mathrm{NADH}, 1 \mathrm{mg} / \mathrm{ml} \mathrm{BSA}, 0.6 \mathrm{U} \mathrm{PK}$ and $0.9 \mathrm{U} \mathrm{LDH}$ ) in a total volume of $100 \mu \mathrm{l}$, unless otherwise explicitly stated. 
In qualitative experiments, where the apparent velocities of different UDPactivated sugars were compared, $10 \mathrm{nM}$ of ng $\zeta$ - 1 and $4 \mathrm{mM} \mathrm{Mg}^{2+}$-ATP were added to the assay buffer and incubated until a stable baseline was observed. The reaction was started upon addition of either $50 \mu \mathrm{M}$ of UNAG, UNAM, or UDP-glucose.

For the titration experiments aiming at determination of the Michaelis Menten parameters for UDP-sugar species, $4 \mathrm{mM} \mathrm{Mg}^{2+}$-ATP and $200 \mathrm{nM}$ (in case of UNAG and UDP-glucose) or $5 \mathrm{nM}$ (in case of UNAM) ng $\zeta_{1} 1$ were added to the assay buffer. Reactions were started by addition of varying concentrations of different substrates (UNAG: 0.31-40 mM, UDP-glucose: 0.31-20 mM, UNAM: 23-750 $\mu \mathrm{M}$ ). For UNAM titration the amount of PK and LDH was increased threefold. While a stable baseline was observed when using a low enzyme

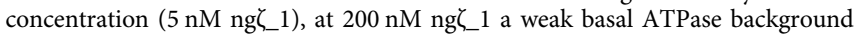
activity was observed. This apparent basal reaction velocity was determined to be in the range of $0.03-0.13 \mathrm{~s}^{-1}$ and was subtracted for baseline correction in these experiments. In experiments aiming at determination of the Michaelis Menten parameters for ATP, $200 \mathrm{nM}$ (in case of UNAG or UDP-glucose) or $10 \mathrm{nM}$ (in case of UNAM) ng $\zeta_{-} 1$ and varying concentrations of $\mathrm{Mg}^{2+}$-ATP from $31.25 \mu \mathrm{M}-4$ $\mathrm{mM}$ were added to the reaction mixture and incubated until a stable baseline was reached. In case of a weak basal ATPase activity a baseline correction was performed as described above. The reaction was started by addition of either 20 mM UNAG or UDP-glucose or $1 \mathrm{mM}$ UNAM.

The apparent initial velocities for each measurement were determined by the Spectra Manager Analysis software (JASCO), converted to apparent $k_{\text {cat }}$ and each measurement was fitted to the Michaelis Menten equation with GraphPad Prism v.5 (GraphPad, La Jolla, USA).

Activity of peptidoglycan synthesis enzymes. MurA and MurC activities were monitored in an assay that couples the release of inorganic phosphate to the cleavage of fluorescent 7 -methylguanosine ${ }^{73}$ by purine nucleoside phosphorylase (PNPase, Sigma-Aldrich, St. Louis, USA). The resulting decrease in fluorescence at $400 \mathrm{~nm}$ (bandwidth $5 \mathrm{~nm}$ ) was measured with a spectrofluorometer (FP-8500, JASCO) using $300 \mathrm{~nm}$ as the excitation wavelength (bandwidth $5 \mathrm{~nm}$ ). MurA reactions were performed in a total volume of $400 \mu \mathrm{l}$ in a buffer containing $50 \mathrm{mM}$ Hepes- $\mathrm{NaOH}$ pH 7.5, $50 \mathrm{mM} \mathrm{NaCl}, 1 \mathrm{mM}$ PEP, $0.5 \mathrm{mM}$ EDTA, $50 \mu \mathrm{M} 7$ methylguanosine and $0.3 \mathrm{U}$ PNPase supplemented with either $50 \mu \mathrm{M}$ UNAG, 50 $\mu \mathrm{M}$ UNAG- $4 \mathrm{P}$ or both $(50 \mu \mathrm{M}$ each). After a stable baseline was reached the reaction was started upon addition of $0.25 \mu \mathrm{M}$ MurA. A potential inhibitory effect of UNAM and UNAM-4P on the MurA activity was tested through the addition of $100 \mu \mathrm{M}$ UNAM or UNAM-4P to a reaction containing $100 \mu \mathrm{M}$ UNAG as substrate.

Similarly, MurC activity was measured in a total volume of $400 \mu$ in a buffer containing $50 \mathrm{mM}$ Hepes-NaOH pH 7.5, $0.1 \mathrm{mM}$ EDTA, $10 \mathrm{mM} \mathrm{MgCl}_{2}, 300 \mu \mathrm{M}$ $\mathrm{Mg}^{2+}$-ATP, $0.5 \mathrm{mM} \mathrm{L}$-Ala, $0.3 \mathrm{U}$ PNPase, $50 \mu \mathrm{M}$ 7-methylguanosine, and either 50 $\mu \mathrm{M}$ UNAM, $50 \mu \mathrm{M}$ UNAM-4P or both. After reaching a stable baseline $2 \mu \mathrm{M}$ MurC were added to start the reaction.

MurB activity was followed spectroscopically by directly monitoring the oxidation of NADPH at $340 \mathrm{~nm}$ in buffer containing $50 \mathrm{mM}$ Tris- $\mathrm{HCl} \mathrm{pH} 8.0,50$ $\mathrm{mM} \mathrm{KCl}$, and $150 \mu \mathrm{M}$ NADPH in a total volume of $100 \mu \mathrm{l}$. Subsequently, either 30 $\mu \mathrm{M}$ EPUNAG, $30 \mu \mathrm{M}$ EPUNAG-4P or both $(30 \mu \mathrm{M}$ each) were added to the reaction which was started upon addition of $50 \mathrm{nM}$ MurB.

Data availability. Coordinates and structure factor amplitudes have been deposited in the Protein Data Bank under accession codes 6EPG, 6EPH and 6EPI. Other data are available from the corresponding author upon reasonable request.

Received: 1 October 2017 Accepted: 2 March 2018

Published online: 27 April 2018

\section{References}

1. Leplae, R. et al. Diversity of bacterial type II toxin-antitoxin systems: a comprehensive search and functional analysis of novel families. Nucleic Acids Res 39, 5513-5525 (2011).

2. Pandey, D. P. \& Gerdes, K. Toxin-antitoxin loci are highly abundant in freeliving but lost from host-associated prokaryotes. Nucleic Acids Res. 33, 966-976 (2005).

3. Yamaguchi, Y., Park, J. H. \& Inouye, M. Toxin-antitoxin systems in bacteria and archaea. Annu Rev. Genet 45, 61-79 (2011).

4. Gerdes, K., Christensen, S. K. \& Lobner-Olesen, A. Prokaryotic toxin-antitoxin stress response loci. Nat. Rev. Microbiol 3, 371-382 (2005).

5. Lobato-Marquez, D., Diaz-Orejas, R. \& Garcia-Del Portillo, F. Toxin-antitoxins and bacterial virulence. FEMS Microbiol Rev. 40, 592-609 (2016).

6. Wang, X. \& Wood, T. K. Toxin-antitoxin systems influence biofilm and persister cell formation and the general stress response. Appl. Environ. Microbiol 77, 5577-5583 (2011).
7. Hauryliuk, V., Atkinson, G. C., Murakami, K. S., Tenson, T. \& Gerdes, K. Recent functional insights into the role of (p)ppGpp in bacterial physiology. Nat. Rev. Microbiol 13, 298-309 (2015).

8. Schuster, C. F. \& Bertram, R. Toxin-antitoxin systems are ubiquitous and versatile modulators of prokaryotic cell fate. FEMS Microbiol Lett. 340, 73-85 (2013).

9. Gerdes, K. \& Maisonneuve, E. Bacterial persistence and toxin-antitoxin loci. Annu Rev. Microbiol 66, 103-123 (2012).

10. Goeders, N. \& Van Melderen, L. Toxin-antitoxin systems as multilevel interaction systems. Toxins (Basel) 6, 304-324 (2014).

11. Pedersen, $\mathrm{K}$. et al. The bacterial toxin RelE displays codon-specific cleavage of mRNAs in the ribosomal A site. Cell 112, 131-140 (2003).

12. Zhang, Y. et al. MazF cleaves cellular mRNAs specifically at ACA to block protein synthesis in Escherichia coli. Mol. Cell 12, 913-923 (2003).

13. Cook, G. M. et al. Ribonucleases in bacterial toxin-antitoxin systems. Biochim Biophys. Acta 1829, 523-531 (2013).

14. Germain, E., Castro-Roa, D., Zenkin, N. \& Gerdes, K. Molecular mechanism of bacterial persistence by HipA. Mol. Cell 52, 248-254 (2013).

15. Kaspy, I. et al. HipA-mediated antibiotic persistence via phosphorylation of the glutamyl-tRNA-synthetase. Nat. Commun. 4, 3001 (2013).

16. Castro-Roa, D. et al. The Fic protein Doc uses an inverted substrate to phosphorylate and inactivate EF-Tu. Nat. Chem. Biol. 9, 811-817 (2013).

17. Ogura, T. \& Hiraga, S. Mini-F plasmid genes that couple host cell division to plasmid proliferation. Proc. Natl Acad. Sci. USA 80, 4784-4788 (1983).

18. Bernard, P. et al. The F plasmid CcdB protein induces efficient ATPdependent DNA cleavage by gyrase. J. Mol. Biol. 234, 534-541 (1993).

19. Gerdes, K. et al. Mechanism of postsegregational killing by the hok gene product of the parB system of plasmid R1 and its homology with the relF gene product of the E. colirelB operon. EMBO J. 5, 2023-2029 (1986).

20. Brantl, S. Bacterial type I toxin-antitoxin systems. RNA Biol. 9, 1488-1490 (2012).

21. Mutschler, H., Gebhardt, M., Shoeman, R. L. \& Meinhart, A. A novel mechanism of programmed cell death in bacteria by toxin-antitoxin systems corrupts peptidoglycan synthesis. PLoS Biol. 9, e1001033 (2011).

22. Mutschler, H. \& Meinhart, A. epsilon/zeta systems: their role in resistance, virulence, and their potential for antibiotic development. J. Mol. Med. 89, 1183-1194 (2011).

23. Ceglowski, P., Boitsov, A., Chai, S. \& Alonso, J. C. Analysis of the stabilization system of pSM19035-derived plasmid pBT233 in Bacillus subtilis. Gene 136, 1-12 (1993).

24. Khoo, S. K. et al. Molecular and structural characterization of the PezAT chromosomal toxin-antitoxin system of the human pathogen Streptococcus pneumoniae. J. Biol. Chem. 282, 19606-19618 (2007).

25. Meinhart, A., Alonso, J. C., Strater, N. \& Saenger, W. Crystal structure of the plasmid maintenance system epsilon/zeta: functional mechanism of toxin zeta and inactivation by epsilon 2 zeta 2 complex formation. Proc. Natl Acad. Sci. USA 100, 1661-1666 (2003).

26. Saraste, M., Sibbald, P. R. \& Wittinghofer, A. The P-loop--a common motif in ATP- and GTP-binding proteins. Trends Biochem Sci. 15, 430-434 (1990).

27. Barreteau, H. et al. Cytoplasmic steps of peptidoglycan biosynthesis. FEMS Microbiol. Rev. 32, 168-207 (2008).

28. Han, Q. et al. Crystal structure of XanthomonasAvrRxo1-ORF1, a type III effector with a polynucleotide kinase domain, and its interactor AvrRxo1ORF2. Structure 23, 1900-1909 (2015).

29. Triplett, L. R. et al. AvrRxol is a bifunctional type III secreted effector and toxin-antitoxin system component with homologs in diverse environmental contexts. PLoS One 11, e0158856 (2016).

30. Schuebel, F. et al. 3'-NADP and 3'-NAADP, two metabolites formed by the bacterial type III effector AvrRxo1. J. Biol. Chem. 291, 22868-22880 (2016).

31. Shidore, T. et al. The effector AvrRxol phosphorylates NAD in planta. PLoS Pathog. 13, e1006442 (2017).

32. Rocker, A. \& Meinhart, A. A cis-acting antitoxin domain within the chromosomal toxin-antitoxin module EzeT of Escherichia coli quenches toxin activity. Mol. Microbiol. 97, 589-604 (2015).

33. Pachulec, E. \& van der Does, C. Conjugative plasmids of Neisseria gonorrhoeae. PLoS One 5, e9962 (2010).

34. Morse, S. A., Johnson, S. R., Biddle, J. W. \& Roberts, M. C. High-level tetracycline resistance in Neisseria gonorrhoeae is result of acquisition of streptococcal tetM determinant. Antimicrob. Agents Chemother. 30, 664-670 (1986).

35. Tabone, M., Ayora, S. \& Alonso, J. C. Toxin zeta reversible induces dormancy and reduces the UDP-N-acetylglucosamine pool as one of the protective responses to cope with stress. Toxins 6, 2787-2803 (2014).

36. Kwon, S. K., Kim, S. K., Lee, D. H. \& Kim, J. F. Comparative genomics and experimental evolution of Escherichia coli BL21(DE3) strains reveal the landscape of toxicity escape from membrane protein overproduction. Sci. Rep. 5, 16076 (2015).

37. Studier, F. W., Daegelen, P., Lenski, R. E., Maslov, S. \& Kim, J. F. Understanding the differences between genome sequences of Escherichia coli 
B strains REL606 and BL21(DE3) and comparison of the E. coliB and K-12 genomes. J. Mol. Biol. 394, 653-680 (2009).

38. Barupal, D. K., Lee, S. J., Karoly, E. D. \& Adhya, S. Inactivation of metabolic genes causes short- and long-range dys-regulation in Escherichia coli metabolic network. PLoS One 8, e78360 (2013).

39. Holm, L., Kaariainen, S., Rosenstrom, P. \& Schenkel, A. Searching protein structure databases with DaliLite v.3. Bioinformatics 24, 2780-2781 (2008).

40. Mizyed, S., Oddone, A., Byczynski, B., Hughes, D. W. \& Berti, P. J. UDP-Nacetylmuramic acid (UDP-MurNAc) is a potent inhibitor of MurA (enolpyruvyl-UDP-GlcNAc synthase). Biochemistry 44, 4011-4017 (2005).

41. Brzozowska, I. \& Zielenkiewicz, U. Regulation of toxin-antitoxin systems by proteolysis. Plasmid 70, 33-41 (2013).

42. Mengin-Lecreulx, D., Flouret, B. \& van Heijenoort, J. Cytoplasmic steps of peptidoglycan synthesis in Escherichia coli. J. Bacteriol. 151, 1109-1117 (1982).

43. Mengin-Lecreulx, D., Flouret, B. \& van Heijenoort, J. Pool levels of UDP Nacetylglucosamine and UDP N-acetylglucosamine-enolpyruvate in Escherichia coli and correlation with peptidoglycan synthesis. J. Bacteriol. 154, 1284-1290 (1983).

44. Mengin-Lecreulx, D., Siegel, E. \& van Heijenoort, J. Variations in UDP-Nacetylglucosamine and UDP-N-acetylmuramyl-pentapeptide pools in Escherichia coli after inhibition of protein synthesis. J. Bacteriol. 171, 3282-3287 (1989).

45. Namboori, S. C. \& Graham, D. E. Enzymatic analysis of uridine diphosphate N-acetyl-D-glucosamine. Anal. Biochem 381, 94-100 (2008).

46. Buckstein, M. H., He, J. \& Rubin, H. Characterization of nucleotide pools as a function of physiological state in Escherichia coli. J. Bacteriol. 190, 718-726 (2008).

47. Ha, S. et al. The kinetic characterization of Escherichia coli MurG using synthetic substrate analogues. J. Am. Chem. Soc. 121, 8415-8426 (1999).

48. Raetz, C. R. et al. Discovery of new biosynthetic pathways: the lipid A story. J. Lipid Res 50, S103-S108 (2009).

49. Ulaganathan, V., Buetow, L. \& Hunter, W. N. Nucleotide substrate recognition by UDP-N-acetylglucosamine acyltransferase (LpxA) in the first step of lipid A biosynthesis. J. Mol. Biol. 369, 305-312 (2007).

50. Wang, X. \& Quinn, P. J. Lipopolysaccharide: biosynthetic pathway and structure modification. Prog. Lipid Res 49, 97-107 (2010).

51. Harvey, R. M. et al. A variable region within the genome of Streptococcus pneumoniae contributes to strain-strain variation in virulence. PLoS One $\mathbf{6}$, e19650 (2011).

52. Chan, W. T. \& Espinosa, M. The Streptococcus pneumoniae pezAT toxinantitoxin system reduces beta-lactam resistance and genetic competence. Front. Microbiol. 7, 1322 (2016).

53. Yao, X. et al. The chromosomal SezAT toxin-antitoxin system promotes the maintenance of the SsPI-1 pathogenicity island in epidemic Streptococcus suis. Mol. Microbiol. 98, 243-257 (2015).

54. Zielenkiewicz, U. \& Ceglowski, P. The toxin-antitoxin system of the streptococcal plasmid pSM19035. J. Bacteriol. 187, 6094-6105 (2005).

55. Ceglowski, P., Boitsov, A., Karamyan, N., Chai, S. \& Alonso, J. C Characterization of the effectors required for stable inheritance of Streptococcus pyogenes pSM19035-derived plasmids in Bacillus subtilis. Mol. Gen. Genet 241, 579-585 (1993).

56. Rosenthal, R. S. Release of soluble peptidoglycan from growing gonococci: hexaminidase and amidase activities. Infect. Immun. 24, 869-878 (1979).

57. Melly, M. A., McGee, Z. A. \& Rosenthal, R. S. Ability of monomeric peptidoglycan fragments from Neisseria gonorrhoeae to damage human fallopian-tube mucosa. J. Infect. Dis. 149, 378-386 (1984).

58. van der Woude, M. W. \& Baumler, A. J. Phase and antigenic variation in bacteria. Clin. Microbiol. Rev. 17, 581-611 (2004).

59. Van Duyne, G. D., Standaert, R. F., Karplus, P. A., Schreiber, S. L. \& Clardy, J. Atomic structures of the human immunophilin FKBP-12 complexes with FK506 and rapamycin. J. Mol. Biol. 229, 105-124 (1993).

60. Voet, D., Gratzer, W. B., Cox, R. A. \& Doty, P. Absorption spectra of nucleotides, polynucleotides, and nucleic acids in the far ultraviolet. Biopolymers 1, 193-208 (1963).

61. Dawson, R. M. C. Data for Biochemical Research (Clarendon Press, Oxford, 1986).

62. Kabsch, W. Automatic processing of rotation diffraction data from crystals of initially unknown symmetry and cell constants. J. Appl. Cryst. 26, 795-800 (1993).

63. Sheldrick, G. M. A short history of SHELX. Acta Crystallogr A 64, 112-122 (2008).

64. McCoy, A. J. et al. Phaser crystallographic software. J. Appl. Cryst. 40, 458-674 (2007).
65. Cowtan, K. Recent developments in classical density modification. Acta Crystallogr D Biol. Crystallogr 66, 470-478 (2010).

66. Cowtan, K. dm: An automated procedure for phase improvement by density modification. Jt. CCP4 ESF-EACBM Newsl. Protein Crystallogr. 31, 34-38 (1994).

67. Emsley, P. \& Cowtan, K. Coot: model-building tools for molecular graphics. Acta Cryst. D60, 2126-2132 (2004)

68. Brunger, A. T. Version 1.2 of the crystallography and NMR system. Nat. Protoc. 2, 2728-2733 (2007)

69. Murshudov, G. N., Vagin, A. A. \& Dodson, E. J. Refinement of macromolecular structures by the maximum-likelihood method. Acta Cryst. D53, 240-255 (1997).

70. Chen, V. B. et al. MolProbity: all-atom structure validation for macromolecular crystallography. Acta Crystallogr D Biol. Crystallogr 66, 12-21 (2010).

71. DeLano, W. L. The PyMOL Molecular Graphics System. (DeLano Scientific, Palo Alto, CA, USA, 2002).

72. Berghauser, J. A reactive arginine in adenylate kinase. Biochim Biophys. Acta 397, 370-376 (1975).

73. Kulikowska, E., Bzowska, A., Wierzchowski, J. \& Shugar, D. Properties of two unusual, and fluorescent, substrates of purine-nucleoside phosphorylase: 7methylguanosine and 7-methylinosine. Biochim Biophys. Acta 874, 355-363 (1986).

\section{Acknowledgements}

We thank C. van der Does (University Freiburg, Germany) for providing plasmid DNA and are grateful to T. Barends, J. Reinstein, and T. Clausen for helpful discussions. We acknowledge C. Roome for support of the crystallographic software and IT, F. Jungblut for technical assistance and the PXII staff for their support in setting up the beamline. Diffraction data were collected at the Swiss Light Source, beamline X10SA, Paul Scherrer Institute, Villigen, Switzerland. We are grateful to I. Schlichting for continuous encouragement and support. This work was financially supported by the Max Planck Society. A. M. is supported by the Chica and Heinz Schaller Foundation, Heidelberg, Germany.

\section{Author contributions}

A.R. and M.P. designed and performed most of the experiments and wrote the manuscript. T.K. performed some of the kinetic experiments and nucleotide activated sugar purifications and wrote the manuscript. R.S. purified and crystallized the protein complex. C.B. performed NMR and analyzed the data. A.M. performed together with A.R. the crystallographic experiments, was involved in experimental design and wrote the manuscript.

\section{Additional information}

Supplementary Information accompanies this paper at https://doi.org/10.1038/s41467 018-03652-8.

Competing interests: The authors declare no competing interests.

Reprints and permission information is available online at http://npg.nature.com/ reprintsandpermissions/

Publisher's note: Springer Nature remains neutral with regard to jurisdictional claims in published maps and institutional affiliations.

Open Access This article is licensed under a Creative Commons Attribution 4.0 International License, which permits use, sharing, adaptation, distribution and reproduction in any medium or format, as long as you give appropriate credit to the original author(s) and the source, provide a link to the Creative Commons license, and indicate if changes were made. The images or other third party material in this article are included in the article's Creative Commons license, unless indicated otherwise in a credit line to the material. If material is not included in the article's Creative Commons license and your intended use is not permitted by statutory regulation or exceeds the permitted use, you will need to obtain permission directly from the copyright holder. To view a copy of this license, visit http://creativecommons.org/ licenses/by/4.0/.

(C) The Author(s) 2018 